\title{
Dynamical Mechanisms Supporting Extreme Rainfall Accumulations in the Houston "Tax Day" 2016 Flood
}

\author{
ERIK R. NIELSEN AND RUSS S. SCHUMACHER \\ Department of Atmospheric Science, Colorado State University, Fort Collins, Colorado
}

(Manuscript received 20 June 2019, in final form 3 October 2019)

\begin{abstract}
This research examines the environmental and storm-scale characteristics of the extreme rainfall and flooding in the Houston, Texas, area on 18 April 2016, known as the "Tax Day" flood. Radar and local mesonet rain gauge observations were used to identify the locations and structures of extreme rain-rateproducing cells, with special attention given to rotating updrafts. To supplement this observation-based analysis, a WRF-ARW simulation of the Tax Day storm in 2016 was examined for the influence of any attendant rotation on both the dynamics and microphysics of the cells producing the most intense short-term (i.e., subhourly to hourly) rainfall accumulations. Results show that the most intense rainfall accumulations in the model analysis, as in the observational analysis, are associated with rotating convective elements. A lowering of the updraft base, enhancement of the low-level vertical velocities, and increased low-level rainwater production is seen in rotating updrafts, compared to those without rotation. These differences are also maintained despite increased hydrometeor loading. The results agree with the findings of previous idealized model simulations that show dynamical accelerations associated with meso- $\gamma$-scale rotation can enhance convective rainfall rates.
\end{abstract}

\section{Introduction}

Extreme rainfall and attendant flash flooding continue to pose significant threats to life and property in the United States. Per annum flash flood fatalities have shown no significant decrease in the last half of the twentieth century (e.g., Ashley and Ashley 2008) with those persons not in a substantial shelter (e.g., driving, camping, or outdoors) having an elevated risk of death (e.g., Spitalar et al. 2014; Terti et al. 2017). Billion dollar losses due to flash flooding occurred every year from 2014 to 2017, and flash flooding was responsible for just under $20 \%$ of the total weather related fatalities over that period, which is second only to the combined fatalities due to heat and cold (NWS 2018b) in that same time. Better understanding of the conditions that lead to flash flooding and improvement of the predictions systems would serve help to improve warning dissemination and forecasting.

The ability to correctly predict the occurrence and magnitude of a flash flood event requires the proper representation of both the meteorological and hydrological processes at play. What happens once the rainfall

Corresponding author: Erik Nielsen, erik.nielsen@colostate.edu hits the ground is dependent on many static and nonstatic hydrologic features (e.g., topography, soil moisture levels, and catchment scale dynamical characteristics). However, the correct prediction of the location, timing, amount, and rate of rainfall is essential to modeling these processes correctly (e.g., Costa 1987; Hapuarachchi et al. 2011; Saharia et al. 2017). While improvements have been made at nowcasting time scales (e.g., Gourley et al. 2017), advanced prediction of this information is needed, since catchment responses can also be seen at similar time scales (e.g., Creutin et al. 2009). Meteorological predictive systems still struggle to accurately predict extreme rainfall accumulations (e.g., Fritsch and Carbone 2004; Novak et al. 2011; Zhang et al. 2016), partially because the predictability characteristics of such events can very across the United States even on the same day (e.g., Nielsen and Schumacher 2016; Nielsen 2016). The utilization of new post processing techniques has proved successful in advancing the multiday predictive horizons of extreme rainfall (e.g., Herman and Schumacher 2018a,b); however, the ability to predict finescale spatialscale hourly to subhourly rainfall accumulations and rain rates still remains a significant challenge (e.g., Schumacher 2017). 
The challenge of extreme precipitation forecasting is compounded, compared to other phenomena, by the fact that prediction of the occurrence and the magnitude (i.e., both the event total and the rate of accumulation) at a subhourly temporal scale is needed. Broadly, the environmental conditions conducive to extreme rainfall are well known (e.g., Maddox et al. 1979; Doswell et al. 1996; Schumacher 2017). Similarly, it is known that extreme rainfall accumulations occur, not surprisingly, where high rain rates are maintained for a long period of time (e.g., Chappell 1986; Doswell et al. 1996). Thus, the resulting duration and rain rate of a particular event are critical constraints on the ability to produce extreme rainfall accumulations. High duration events, often associated with backbuilding or quasi-stationary mesoscale convective systems (MCSs), have been been the subject of a large body of research (e.g., Bluestein and Jain 1985; Chappell 1986; Doswell et al. 1996; Schumacher and Johnson 2005; Schumacher 2009; Nielsen et al. 2016b) and, generally, are driven by strong system scale and environmental interactions as the convective system organizes and matures (e.g., cold pool interactions; mesoscale convective vortex, MCV, development; or how an MCS orients to a synoptic-scale boundary).

Comparatively, the processes that determine the rain rate of the system operate at the system scale and the scales of the individual convective elements. The controlling processes include updraft strength, the precipitation efficiency (related to the ongoing microphysical processes, among others; Sui et al. 2007), and the water vapor mixing ratio of the rising air [See Eq. (2) in Doswell et al. (1996)], which, given the chaotic nature of moist convection (e.g., Lorenz 1969; Zhang et al. 2006; Melhauser and Zhang 2012; Nielsen and Schumacher 2016) and differences in model microphysics (e.g., Khain et al. 2015), are difficult to constrain at the needed lead times. From a flash flooding perspective, the rainfall rate is known to be an important factor in determining the resulting flash flood potential, with harmful impacts increasing with the rain rate (e.g., Kelsch et al. 2001; Kelsch 2001; Kandel et al. 2004; Mohamadi and Kavian 2015). The predictive challenges and hydrologic importance motivate the need to examine the processes that allow for the most intense rainfall rates to be maintained.

Recent observational studies (Smith et al. 2001; Duda and Gallus 2010; Hitchens and Brooks 2013; Nielsen and Schumacher 2019) have shown that extreme rainfall rates can be produced and maintained by supercell thunderstorms and other meso- $\gamma$-scale rotation, despite the previous notion that such storms could not produce such rain rates because of low precipitation efficiency (e.g., Marwitz 1972; Foote and Fankhauser 1973; Browning 1977). Supercells and hail producing storms have even been responsible for world record accumulations (Dalrymple 1937) and some of the most intense flash floods in U.S. history (Smith et al. 2018, 2019). Additionally, concurrent, collocated tornado and flash flood events, known as "TORFF" events (Nielsen et al. 2015, 2016a; Bunkers and Doswell 2016), occur frequently in the United States (e.g., Nielsen 2019). These studies point to the importance of rotating storms in producing extreme rainfall accumulations and rates.

Nielsen and Schumacher (2018) showed, using idealized simulations, that rotation associated with intense 0-1 km shear, can enhance rain rates through dynamic lifting from induced vertical perturbation pressure gradient forces [see section 2.5.3 of Markowski and Richardson (2010)] associated with rotation that are not present in nonrotating storms. The resulting rotationally induced dynamic lifting can aide in maximizing rain rates, first, by dynamically enhancing the updraft and, second, lifting otherwise negatively buoyant parcels that still contain moisture and instability to their level of free convection. These rotational precipitation enhancement mechanisms serve as a dynamical explanation for the ability for storms with meso- $\gamma$-scale rotation, including supercells, to produce extreme rainfall accumulations and intense rain rates. Furthermore, it offers a physical explanation for the frequency of TORFF events in the United States.

Many high profile flash flooding events with concurrent and collocated tornado threats (i.e., TORFFs) have occurred in and around Houston, Texas, in recent years. This includes floods on 28 April 2009; 25-26 May 2015'; 18 April $2016^{2}$ (Lindner and Fitzgerald 2016); 2530 August 2017, associated with Hurricane Harvey (NWS 2018a); and recently 18-19 September 2019, associated with Tropical Storm Imelda. Specifically, these events have been associated with historically intense flooding and rainfall rates with embedded rotation on various scales throughout each event. The overall prevalence of such events in this region, combine with a dense network of operational radars and rain gauges from civil authorities, provides an excellent opportunity to examine the meteorological

\footnotetext{
${ }^{1}$ This flood is locally known as the "Memorial Day" flood as it occurred on the weekend of the Memorial Day holiday in the United States.

${ }^{2}$ This flood is known as the "Tax Day" flood since it occurred on the deadline to file federal taxes in the United States, which is colloquially known as Tax Day.
} 
characteristics of these events and determine if the results of Nielsen and Schumacher (2018) are applicable outside of the previously examined idealized framework.

This research serves to extend the idealized simulations of Nielsen and Schumacher (2018) by examining a full spatially heterogeneous simulation and performing a detailed modeling and observational analysis of the 18 April 2016 Houston "Tax Day" flood, which led to 8 fatalities and damage to thousands of homes and automobiles. It is hypothesized, following Nielsen and Schumacher (2018), that the most intense rain rates are associated with embedded rotating features and possess more intense low-level updraft structures associated with the dynamical effects of rotation. Section 3 describes the "Tax Day" 3 flood event in detail, section 2 presents the methods, section 4 the results of the event analysis, section 5 the results of the model analysis, and section 6 a discussion and summary of the manuscript.

\section{Methods}

\section{a. Observational analysis}

An observational analysis is presented that is an examination of the convective structure and evolution of the Tax Day storm using single and dual-pol radar observations from the Houston/Galveston, Texas, NEXRAD (KHGX) radar system, where specific attention is given to any rotating features. This analysis was accomplished using Level II reflectivity and velocity data, as well as specific differential phase $\left(K_{\mathrm{dp}}\right)$ calculated from the Level II radar data. The Gibson Ridge GRLevel2 Analyst software package (http://www.grlevelx.com/ gr2analyst/) is used to analyze the data and calculate the $K_{\mathrm{dp}}$ for the event. Additionally, the normalized rotation (NROT) product, as derived in the GRLevel2 Analysts software package, is also used as an objective method to quantify the strength of any present rotation and, more importantly, provide a level comparison between various analysis times. NROT is a derived product that can be, at its most basic level, viewed as the azimuthal shear that is normalized to take into account the effects of beam spreading. Any normalized values of NROT above 1 are considered significant, while values above 2.5 are considered extreme [see footnote 2 of Meng and Yao (2014)]. However, as previously mentioned, the NROT field is used mainly to compare the strength of the rotation at different times

\footnotetext{
${ }^{3}$ The quotations will be dropped from this point forward.
}

within this event, as opposed to quantifying the strength of the rotating features compared to other events or directly to the modeling analysis.

High geospatial density rain gauge data are used to evaluate the precipitation produced by varying convective features within the MCS, where the features are identified and characterized by the aforementioned radar data. The rainfall data are obtained from the Harris County Flood Control District's (HCFCD) Harris County Flood Warning System (HCFWS; HCFCD 2019). This network, at the time of this analysis, contains 163 rain gauges spread over the Houston Metropolitan Area, which provide 5-min rainfall accumulation observations with a minimum detection threshold of $\sim 1 \mathrm{~mm}$ (0.04 in.). The high temporal nature allows for near-real-time interrogation of the rainfall being produced by an individual convective element embedded within the MCS.

Mesoscale and synoptic data are obtained from the Rapid Refresh model (RAP; Benjamin et al. 2016) analysis at various times throughout the event. These data are supplemented by wind shear information obtained from the Storm Prediction Center's Mesoscale Analysis (Bothwell et al. 2002; SPC 2018). Additionally, Stage-IV gridded precipitation data (Lin and Mitchell 2005) are used to regionally evaluate any model precipitation forecasts.

\section{b. Model analysis}

Operational numerical models did not forecast the severity, spatial coverage, or general location of this event well (not shown). Similar problems were seen in the operational High-Resolution Rapid Refresh (HRRR; Smith et al. 2008, https://rapidrefresh.noaa.gov/hrrr/), despite rapid data assimilation updates. However, the 0000 UTC 18 April 2016 initialization of experimental version of the HRRR (HRRRx) at the time, captured the overall evolution and severity of the event well (cf. Figs. 1a,b). For this reason, the Weather Research and Forecasting (WRF) Model Advanced Research Core (WRF-ARW, Klemp et al. 2007; Skamarock et al. 2008; Skamarock and Klemp 2008) initial and boundary conditions for the 0000 UTC 18 April 2016 initialization of the HRRRx were obtained from the Earth System Research Laboratory (ESRL). These files were then used to reproduce the HRRRx 3-km horizontal grid-spacing forecast using WRF-ARW version 3.6 and the same physics and model specifics as used in the original HRRRx run. An additional high-resolution nest with horizontal grid spacing of $600 \mathrm{~m}$ was placed within the original HRRRx covering southeastern Texas (extent shown in Fig. 1c). The most pertinent model specifics include $1800 \times 10603-\mathrm{km}$ grid-spacing outer domain, $1001 \times 901600-\mathrm{m}$ inner 

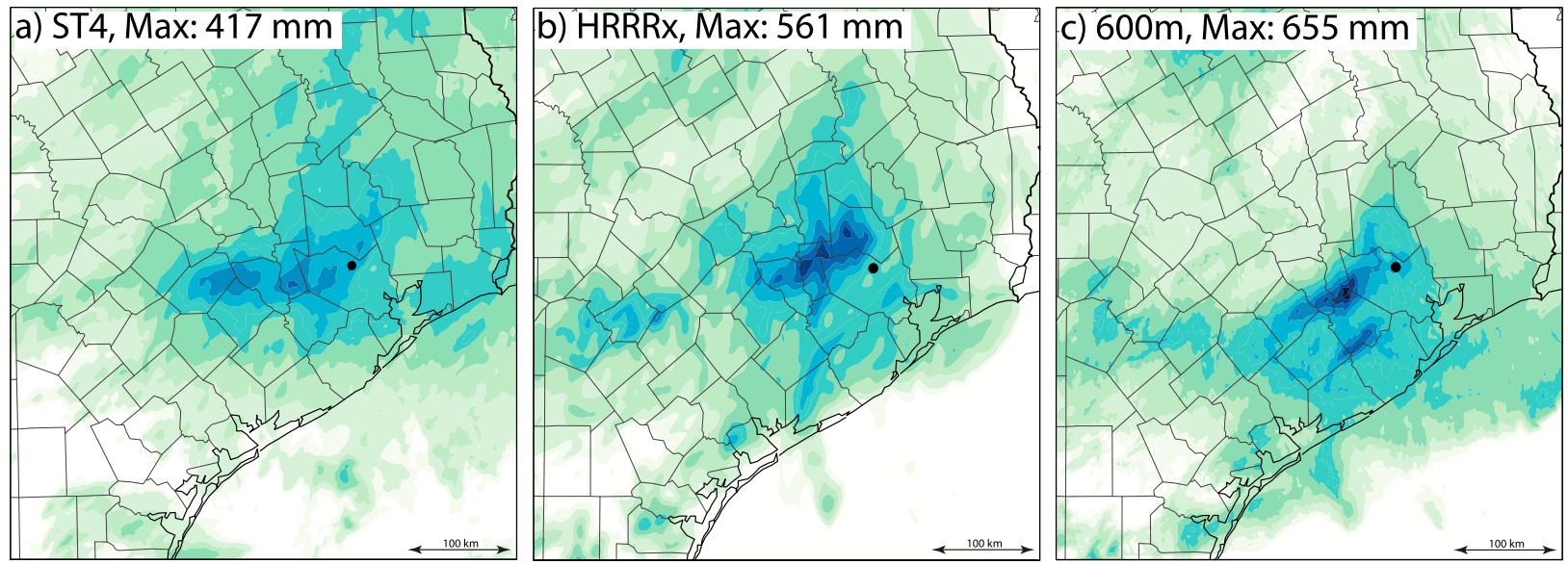

$\begin{array}{lllllllllll}5 & 10 & 25 & 50 & 100 & 150 & 200 & 300 & 400 & 500 & 600\end{array}$

FIG. 1. The 22-h precipitation accumulation valid 2200 UTC 18 Apr 2016 from (a) the Stage-IV precipitation analysis (ST4; Lin and Mitchell 2005), (b) the 0000 UTC 18 Apr 2018 initialization of the experimental High-Resolution Rapid Refresh (HRRRx) model, and (c) the 600-m grid-spacing inner domain initialized within the HRRRx. Geographic extent in figures corresponds to that of the highresolution inner domain. Black dot represents the location of George H.W. Bush Intercontinental Airport (KIAH).

domain, stretched vertical grid with 51 levels in both domains, no cumulus parameterization in either domain, no feedback between domains, Thompson aerosolaware microphysics on both domains (Thompson and Eidhammer 2014), RRTMG longwave and shortwave radiation on both domains (Mlawer et al. 1997), Rapid Update Cycle (RUC) land surface model on both domains (Smirnova et al. 1997, 2000, 2016), and Mellor-Yamada-Nakanishi-Niino planetary boundary layer scheme on both domains (MYNN; Mellor and Yamada 1982; Nakanish 2001; Nakanishi and Niino 2004). While the Thompson and Eidhammer (2014) microphysics scheme was mainly chosen as to replicate the HRRRx model physics suite, it also is a pertinent choice to a study focusing on precipitation, given its ability to incorporate aerosol activation effects and explicitly predict ice nuclei, cloud condensation nuclei, and droplet number concentrations. The simulation was run for $22 \mathrm{~h}$, ending 2200 UTC 18 April 2016. Model output was archived at 5-min intervals on the inner domain and 30-min intervals on the outer domain. The inner $600 \mathrm{~m}$ domain serves as the analysis domain for this research. Specific focus is given to the relationships between updrafts, rotation, and precipitation formation processes.

\section{Event overview}

The "Tax Day" flood of 18 April 2016 in Houston was responsible for significant rainfall (Figs. 2a,b) and flooding across the metropolitan area (Fig. 2c). Broad areas of 150 to $300 \mathrm{~mm}$ of rainfall were seen over a large portion of southeastern Texas (Fig. 1a) throughout the event. Some portions of western Harris county received over $400 \mathrm{~mm}$ of rain over a 12-h period, as observed by the Harris County Flood Control District (HCFCD) rain gauge network, with total values over $550 \mathrm{~mm}(\sim 22$ in.) seen in far western Waller County. An event maximum of $\sim 600 \mathrm{~mm}$ (23.5 in.) was observed over 14.5-h period in Pattison, Texas (Waller County), from a local observer (Lindner and Fitzgerald 2016). According to the updates to NOAA Atlas 14, which were published after this event, the maximum 12-h rainfall corresponded to extrapolated exceedance probabilities between $1.0 \%$ and $0.5 \%$ (i.e., $\sim 100-200-\mathrm{yr}$ event, Figs. 2a,b; Lindner and Fitzgerald 2016; Perica et al. 2018), depending on the location. The rainfall led to significant flooding along the creeks and bayous in eastern and northern Harris County, with channel water elevation exceedance probabilities less than $0.2 \%$ (i.e., 500 -yr event) observed (Fig. 2c). A total of eight fatalities were directly associated with flash flooding from the event, all from drownings in vehicles. Additionally, approximately 40000 vehicles and 10000 homes were damaged (Lindner and Fitzgerald 2016; NOAA 2016). While the flash flooding served to be the main hazard associated with the Tax Day storm, tornado warnings were issued by the Houston/Galveston WFO, and post event surveys identified that three EF-0 tornadoes occurred within the storm system. This led to the Tax Day storm being identified as a "verified" TORFF event (i.e., a tornado and flash flood were observed to be "concurrent and collocated" 

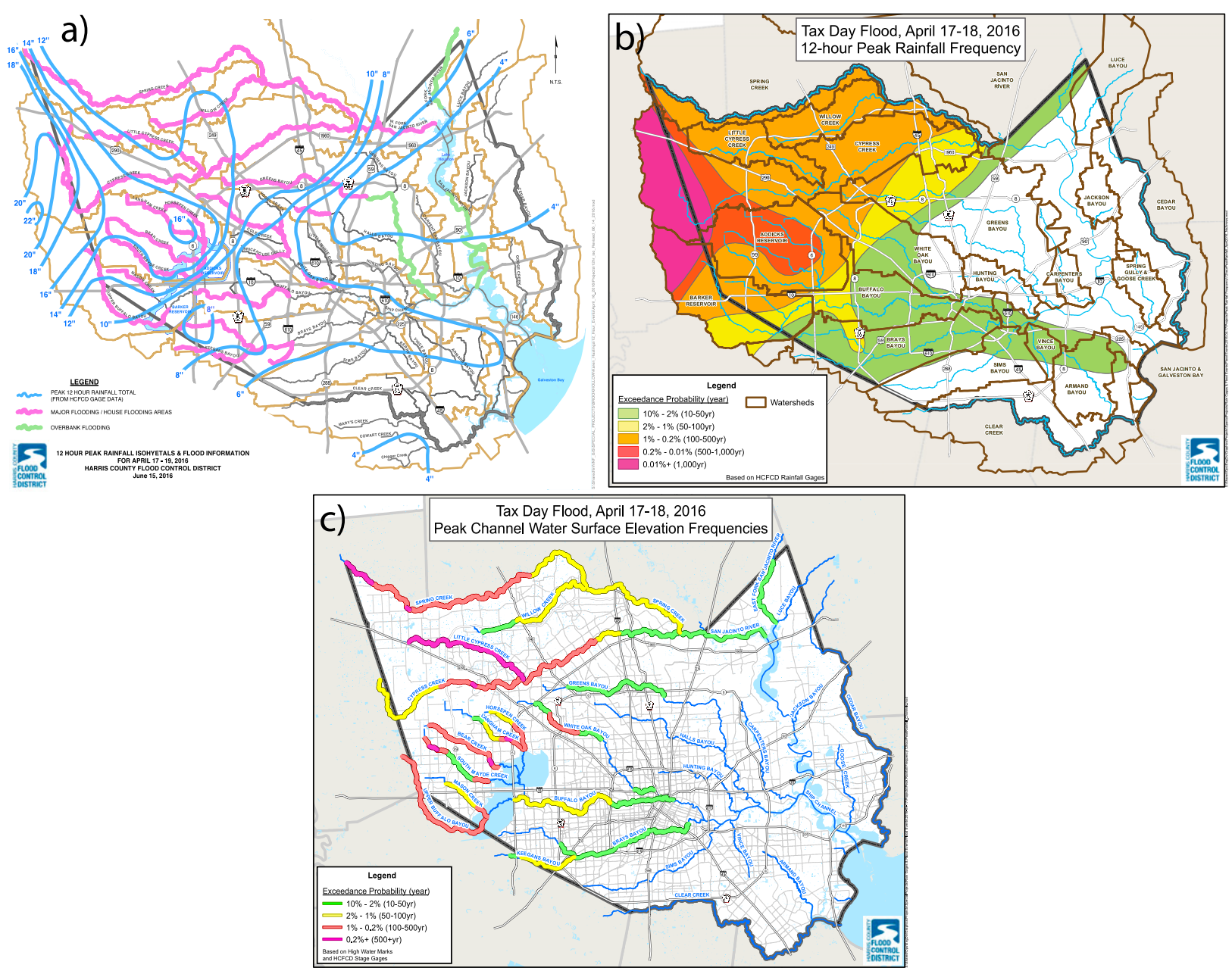

FIG. 2. (a) Harris County Flood Control District rain gauge analysis (blue lines) and noted channel flooding (pink lines) for the 18 Apr 2016 Tax Day flood. (b),(c) Return period frequency analysis of rainfall and streamflow, respectively, from the same source. Plots are reproduced from Lindner and Fitzgerald (2016). It should be noted that the rainfall recurrence intervals listed here are likely to have changed with the recent release of NOAA Atlas 14 data for Texas (Perica et al. 2018).

within particular distance and time thresholds) in Nielsen (2019).

The rainfall in and around the Houston area on 18 April 2016 was the result of a deep, slow moving upper-level system that was anchored over the Great basin, due to the presence of an "omega" blocking ridge (e.g., Namias 1951; Berry et al. 1953) in the eastern United States (Figs. 3a,b) that is a known pattern for producing extreme precipitation events (e.g., Milrad et al. 2019). The counterclockwise flow around the stationary upper-level system advected increased amounts of moisture off the Gulf of Mexico into the central United States (Figs. 3a,b,d). Warm-air advection at midlevels was maximized in the southern portions of the United States, specifically along the Texas Gulf Coast (Fig. 3c). Shortwaves embedded around the closed upper-level low (Fig. 3b) continued to initiate convection throughout the central and eastern United States, until the upper-level system moved into the Atlantic Ocean by 24 April 2016 (not shown). The position of the cutoff upper-level trough and the blocking ridge led to relatively weak winds throughout the column in the Houston area (Fig. 3a), with the maximum wind speeds located below $850 \mathrm{hPa}$ (Fig. 3c).

Convection initiated in the Houston area associated with an upper-level shortwave near 2300 UTC 17 April 2016 (not shown) and fairly rapid $11 \mathrm{~mm}$ increase in PWAT between 1715 and 2345 UTC 18 April 2016, as seen in global positioning system (GPS) water vapor retrievals from the Lake Jackson, Texas (TXAG), SuomiNet station (not shown; Ware et al. 2000). Over the next four hours the convection continued to intensify into the overnight period associated with an additional (albeit smaller) increase in total column moisture 

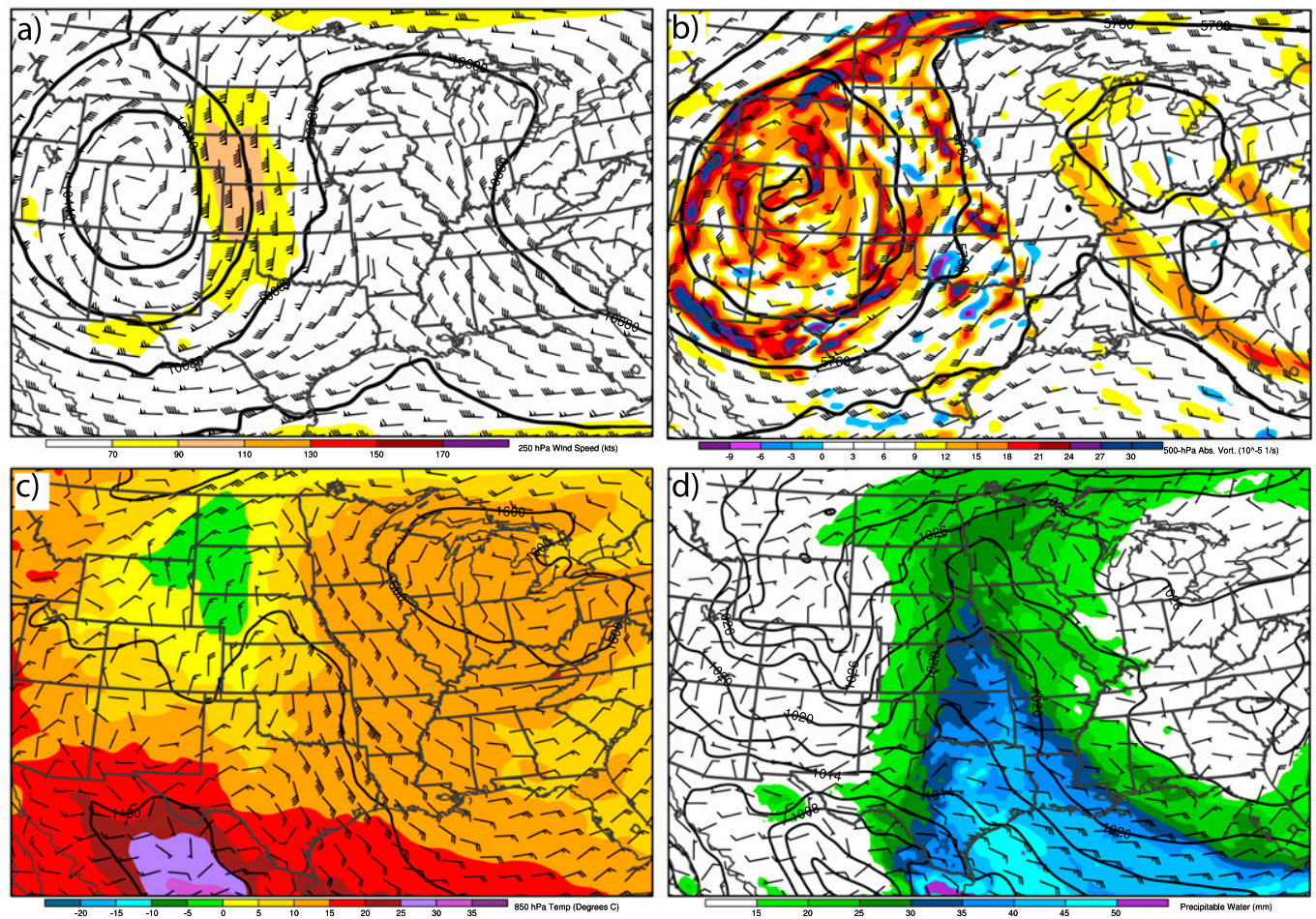

FIG. 3. (a)-(d) Rapid Refresh (RAP; Benjamin et al. 2016) analyses valid at 0000 UTC 18 Apr 2016. (a) 250-hPa isotachs (shaded every $20 \mathrm{kt}$ over $70 \mathrm{kt}, 1 \mathrm{kt}=0.5144 \mathrm{~m} \mathrm{~s}^{-1}$ ), 250-hPa geopotential height (contoured every $120 \mathrm{~m}$ ), and $250-\mathrm{hPa}$ wind barbs (half barb $=5 \mathrm{kt}$, full barb $=10 \mathrm{kt}$, pennant $=50 \mathrm{kt}$,). (b) Absolute vorticity at $500-\mathrm{hPa}$ $\left(\times 10^{-5} \mathrm{~s}^{-1}\right.$, shaded every $3 \times 10^{-5} \mathrm{~s}^{-1}$ above $\left.-9 \times 10^{-5} \mathrm{~s}^{-1}\right), 500$-hPa geopotential height (contoured every $\left.60 \mathrm{~m}\right)$, and 500-hPa wind barbs. (c) 850-hPa geopotential height (contoured every $25 \mathrm{~m}$ ), 850-hPa wind barbs, and 850-hPa temperature (shaded every $5^{\circ} \mathrm{C}$ from $-20^{\circ}$ to $35^{\circ} \mathrm{C}$ ). (d) Precipitable water (shaded contours every 5 mm for values from 10 to $50 \mathrm{~mm}$ ), $10 \mathrm{~m}$ wind barbs, and mean sea level pressure (MSLP) (contoured every $3 \mathrm{hPa}$ ).

(Fig. 4a) and instability (Fig. 4b) off the Gulf of Mexico, with PWAT exceeding $50 \mathrm{~mm}$ and MUCAPE exceeding $1500 \mathrm{~J} \mathrm{~kg}^{-1}$ in the RAP analysis. The SuomniNet observed rapid increase in moisture preceded this increase in instability that also coincided with the development of a robust nocturnal low-level jet (LLJ), which approached $24 \mathrm{~m} \mathrm{~s}^{-1}$ at $900 \mathrm{hPa}$ by 0300 UTC 18 April 2018 (Fig. 4b). No representative operational upper-air observations were available, since this portion of the upper Texas coast is located in an upper-air observation hole (Benoit et al. 2018). However, the Houston/Galveston NEXRAD (KHGX) velocity-azimuth display (VAD; Atlas 1964; Browning and Wexler 1968) profiles (Fig. 5) show the rapid increase in low-level winds associated with the LLJ and a resulting increase in $0-1 \mathrm{~km}$ shear, as denoted in the 0300 UTC RAP analysis (Fig. 4b). Additionally, the SPC mesoanalysis at 0300 UTC (SPC 2018) shows $0-1 \mathrm{~km}$ shear values over $15 \mathrm{~m} \mathrm{~s}^{-1}$ (Fig. 4c) with the majority of the atmospheric shear being located in the low levels (cf. Figs. 4c,d). Continued VAD profiles show that similar wind profiles and low-level shear values as those depicted near 0249 UTC 18 April 2016 in Fig. 5 are maintained throughout the event (not shown), which also led to intense storm relative inflow at low levels as the convective storm motion was roughly toward the east.

The previously isolated convection began to congeal beginning about 0230 UTC 18 April 2016 (not shown). The cell mergers continued and the intensity of the convection increased, with a broad area of $50 \mathrm{dBZ}$ cores present by 0430 UTC that same day (Fig. 6a). Furthermore, a developing bookend vortex and smaller rotating features were also visible in the radar imagery at this time Fig. 6d). The intense rainfall and the bookend vortex led to reinforcement of a low-level cold pool boundary perpendicular to the onshore low-level jet. This created a slow-moving arc of rainfall along the edges of the boundary (Fig. 6b) that contained many rotating features on varying scales (Fig. 6e), some of which were tornado warned. As intense rainfall continued, the resulting cold pool strengthened and the MCS was able to move east, against the intense low-level jet (Figs. 6c,f). The now forward propagating MCS began weakening by 1130 UTC and moved into the Gulf 

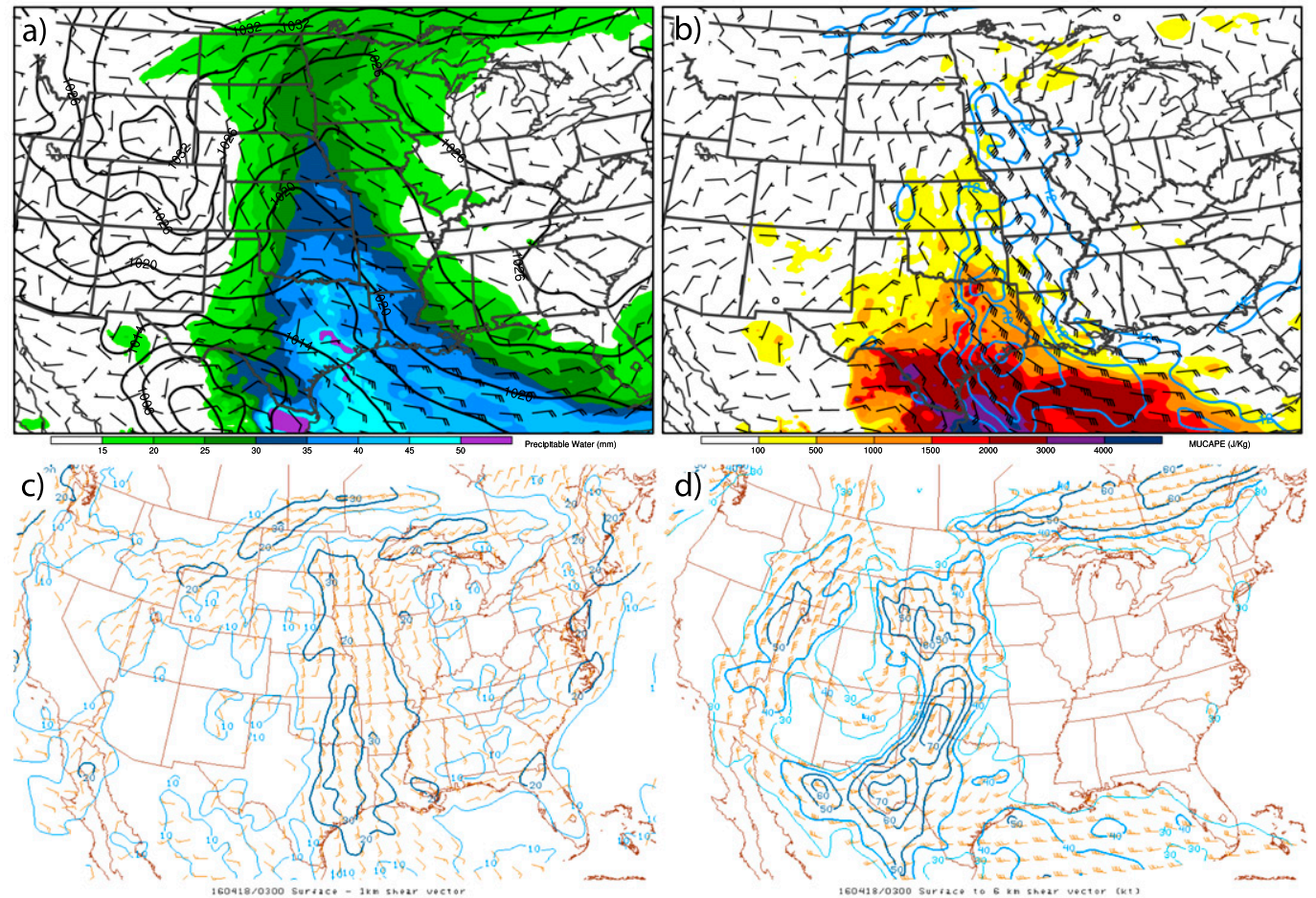

FIG. 4. (a),(b) Rapid Refresh (RAP; Benjamin et al. 2016) analyses valid at 0300 UTC 18 Apr 2016. (a) Precipitable water (shaded contours every $5 \mathrm{~mm}$ for values from 10 to $50 \mathrm{~mm}$ ), 10-m wind barbs, and mean sea level pressure (MSLP) (contoured every $3 \mathrm{hPa}$ ). (b) Most Unstable CAPE (MUCAPE; shaded at $100 \mathrm{~J} \mathrm{~kg}^{-1}$ then every $500 \mathrm{~J} \mathrm{~kg}^{-1}$ above $500 \mathrm{~J} \mathrm{~kg}^{-1}$ ), 900-hPa wind barbs, and 900-hPa isotachs (contoured every $3 \mathrm{~m} \mathrm{~s}^{-1}$ above $12 \mathrm{~m}^{-1}$ ). (c) $0-1-\mathrm{km}^{-}$and (d) 0-6-km environmental shear from the Storm Prediction Center mesoscale analysis (SPC 2018).

of Mexico by 1700 UTC 18 April 2016, as light stratiform precipitation continued in the Houston area until approximately 1900 UTC.

\section{Results: Observational analysis}

While heavy rainfall was recorded throughout the event by many HCFCD rain gauges, two main periods of especially intense rainfall were observed by gauges on the north side of the Houston metro area: the first period, between 0430 and 0630 UTC and, the second period, between 0700 and 0900 UTC (Fig. 7). Each period was associated with observed intense rain rates, which in some cases were over $240 \mathrm{~mm} \mathrm{~h}^{-1}$ at a 5-min time scale (Fig. 7). The 5-min rain rates were maximized at the beginning of each period, but the

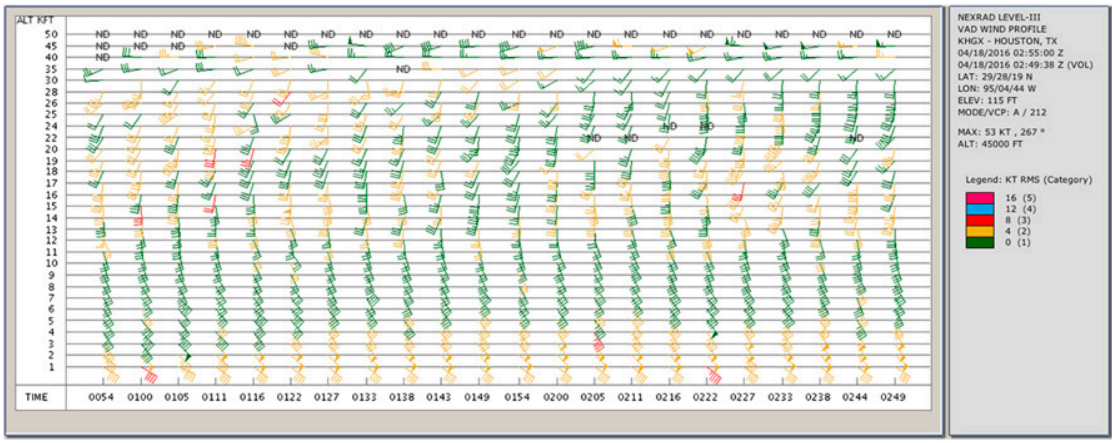

FIG. 5. Time series of velocity-azimuth display (VAD) derived winds from the Houston/Galveston, TX (KHGX), NEXRAD radar from 0054 to 0249 UTC 18 Apr 2016. Wind barbs follow same convention as in Fig. 3, altitude is in thousands of feet above sea level $(1000 \mathrm{ft}=$ $0.3048 \mathrm{~km}$ ), and wind barb color denotes estimated root-mean-square error (RMS) by algorithm. 


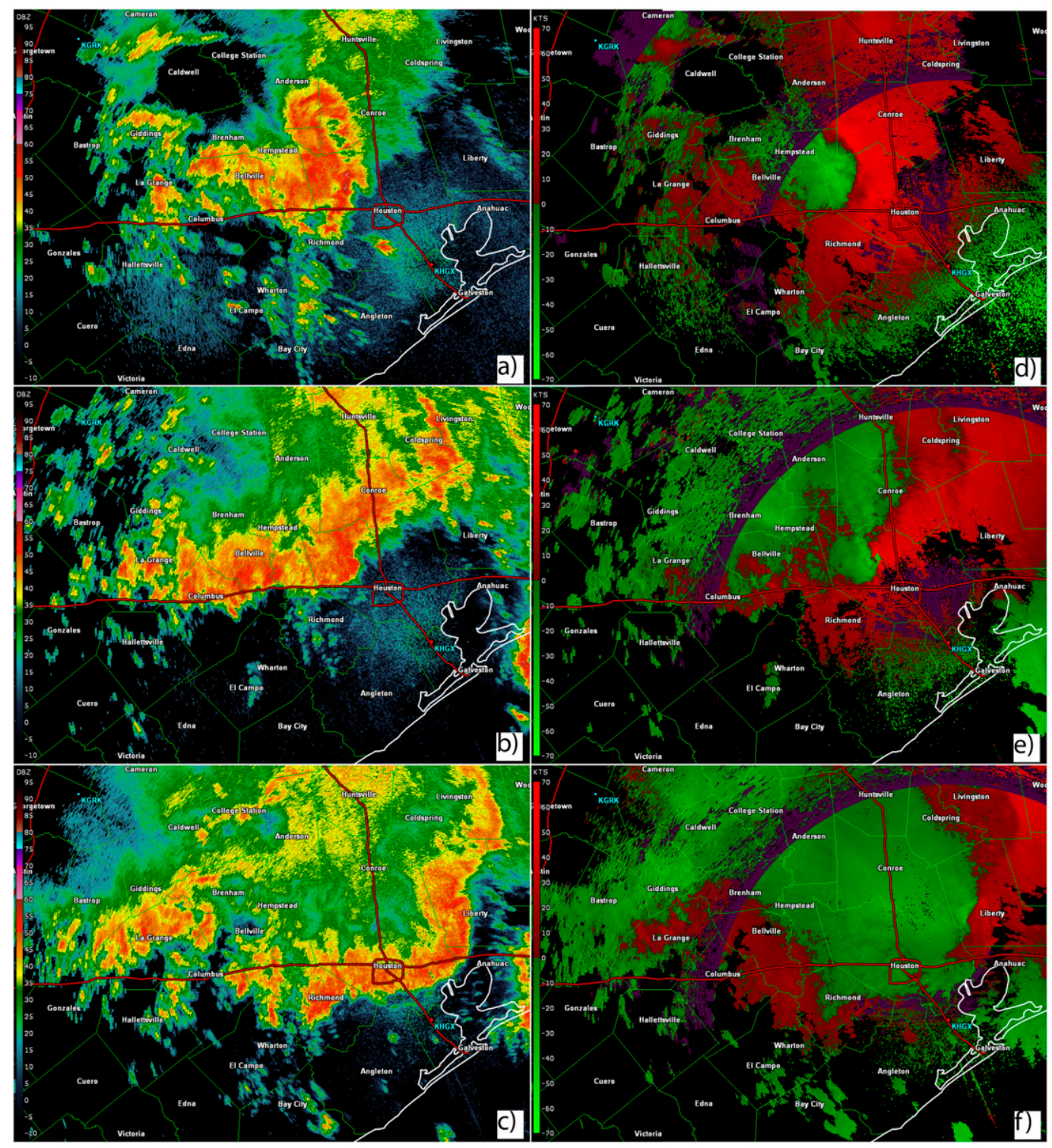

FIG. 6. (a)-(c) Radar reflectivity and (d)-(f) velocity from the Houston/Galveston (KHGX) radar valid (a),(d) 0432, (b),(e) 0822, and (c),(f) 1059 UTC 18 Apr 2016.

storms still produced large short-term rainfall accumulations (i.e., $60-120 \mathrm{~mm} \mathrm{~h}^{-1}$ at a 5 -min time scale) following the initial local temporal maximums.

The first period, between 0430 and 0630 UTC 18 April 2016, was associated with the development and maintenance of an embedded, rotating, and tornado-warned feature that moved across the northern Houston metro area. Radar imagery from this period (Fig. 8) shows robust convection sustained along and behind the leading edge of this feature for the majority of the period (Figs. 8a,e,i,m). The broad elongated rotation along the leading edge (Figs. 8b,f,j,n,d,h,l,p) is persistent through the period as well. The maximum rotation, per the NROT algorithm, is seen near 0500 UTC (Figs. 8f,h), just before the tornado warning is issued. Throughout the period the broad, north-south elongated regions of rotation (Figs. 8d,h,l,p) are located just upstream from a contiguous region of $K_{\mathrm{dp}}$ values greater than $3^{\circ} \mathrm{km}^{-1}$ of similar spatial extent (cf. Figs. 8d,h,l,p and Figs. 8c,g,k,o), with local maximums in $K_{\mathrm{dp}}$ in the broad $3^{\circ} \mathrm{km}^{-1} K_{\mathrm{dp}}$ region in the $4^{\circ}-5+{ }^{\circ} \mathrm{km}^{-1}$ range corresponding to local maximums in the upstream rotation. The northwest displacement of the precipitation from the strongest rotation is likely a result of the mean storm-relative flow being to the northwest in the event, driven especially by the flow at mid- to upper 
levels (e.g., Fig. 5). Furthermore, nonrotating regions had lower $K_{\mathrm{dp}}$ values in the $0.5^{\circ}-2^{\circ} \mathrm{km}^{-1}$ range. The local enhancement of $K_{\mathrm{dp}}$ by the most intense rotation within the broad rotating region of $3+{ }^{\circ} \mathrm{km}^{-1} K_{\mathrm{dp}}$ can be seen south of gauge $\mathrm{E}$ in Figs. $8 \mathrm{c}$ and $8 \mathrm{~d}$; north of gauge $\mathrm{F}$ and $\mathrm{G}$ in Figs. $8 \mathrm{~g}$ and $8 \mathrm{~h}$; and west of two regions of locally most intense rotation in Figs. 80 and $8 \mathrm{p}$. The relationship is important to note, since $K_{\mathrm{dp}}$ is proportionate to liquid water content and has a nearly linear relationship to rain rate (e.g., Kumjian 2013a,b). ${ }^{4}$ Thus, the rotating updrafts are spatially associated with the regions of most intense liquid water content as diagnosed by the radar on a broad and local scale. This make sense given that the rotation is likely a representation of the updraft location, and the $K_{\mathrm{dp}}$ values are a representation of the hydrometeors.

The rain gauge data illustrates that the highest rain rates are, indeed, associated with the most intense $K_{\text {dp }}$ values. Gauges C (Fig. 7c) and D (Fig. 7d) both show a rapid increase in observed rainfall accumulations beginning at 0440 UTC, right as the most intense $K_{\mathrm{dp}}$ values (i.e., $4+{ }^{\circ} \mathrm{km}^{-1}$ ) reached the gauges ( $5 \mathrm{~min}$ before Figs. $8 \mathrm{a}-\mathrm{d}$ ). In the 15 -min period between 0440 and 0455 UTC ( 5 min before Figs. $8 \mathrm{e}-\mathrm{h}$ ), gauges $C$ and D recorded $40.64 \mathrm{~mm}$ and $44.70 \mathrm{~mm}$ of rain, respectively (Figs. 7c,d). This period corresponded to the passing of the locally intense $4^{\circ} \mathrm{km}^{-1} K_{\mathrm{dp}}$ structure associated with local maximum of rotation in the leading edge of the convection. Furthermore, once the locally intense $K_{\mathrm{dp}}$ feature passes gauge locations, intense rainfall is still measured (Figs. 7c,d), given that intense convection is still ongoing in the region (Figs. 8a,c,e,g). However, the rainfall rates are not to the magnitude of that seen with the rotating portion of the line.

The same pattern can be seen across the rest of the gauges presented in Fig. 7 extrapolating out in time as the rotating feature moves off to the east-northeast. For instance, gauge $\mathrm{G}$ (Fig. $7 \mathrm{~g}$ ) shows a rapid increase in rain rate at $0455 \mathrm{UTC}$, right as a locally high $K_{\mathrm{dp}}$ feature $\left(5+{ }^{\circ} \mathrm{km}^{-1}\right.$ region south gauge $\mathrm{E}$ in Fig. $\left.8 \mathrm{c}\right)$ reaches its location (between time shown in Figs. 8a-d

\footnotetext{
${ }^{4}$ As $K_{\mathrm{dp}}$ can be influenced by large hail, it is worth noting that no hail reports were documented during this event in the Houston area. However, the operational hydrometeor classification algorithm from the KHGX radar denoted "hail with rain" aloft for the majority of the period. This highlights the usefulness of $K_{\mathrm{dp}}$ for a proxy for liquid water content in this particular scenario, as it is particularly useful for rain-rate estimation when hail and rain are mixed (e.g., Balakrishnan and Zrnić 1990; Giangrande and Ryzhkov 2008).
}

and Figs. 8e-h). By the time the high $K_{\mathrm{dp}}$ structure moves away from the gauge at 0510 UTC (Figs. 8i-1), $\sim 58 \mathrm{~mm}$ of rain accumulated $\left(\sim 232 \mathrm{~mm} \mathrm{~h}^{-1}\right.$; Fig. $\left.7 \mathrm{~g}\right)$, including a $\sim 328 \mathrm{~mm} \mathrm{~h}^{-1}$ rain rate at a 5-min time scale. However, $60-120 \mathrm{~mm} \mathrm{~h}^{-1}$ rain rates at a 5 -min time scale are observed in the intense convection behind the high $K_{\mathrm{dp}}$ structure, until the rain gauge stops reporting. During the first period of intense rainfall, the gauges presented in Fig. 7 show that extreme 5-min accumulations are observed associated with a locally intense $4^{\circ}-5^{\circ} \mathrm{km}^{-1}$ $K_{\mathrm{dp}}$ structures that are just upstream of the regions of most intense rotation. The 5-min rainfall observations behind these high $K_{\mathrm{dp}}$ structures are still quite impressive, but not as extreme.

The second period between 0700 and 0900 UTC 18 April 2016, similar to the first, was associated with high 5-min rain rates (Fig. 7) and the development/maintenance of another embedded rotating feature. The rotating feature in question was embedded in the MCS at the southeastern corner of the convective line (for regional view Figs. 6b,e) and moved east over the period. The rotation initially became evident in the radar data shortly after 0700 UTC (not shown). The main convective portion associated with the rotation reaches the outskirts of the Houston metro by about 0730 UTC (Fig. 9a). The convection with the embedded rotation continues to strengthen, and broaden, as it moves eastward until approximately 0840 UTC (Figs. 911 ), at which point the rotation begins to weaken as the convection crosses Interstate 45. Multiple tornado warnings were issued during the period (Figs. 10 and 11) on the north and northwest side of the Houston metro.

As aforementioned in the first period of intense rainfall, there is a broad, persistent region of $3+{ }^{\circ} \mathrm{km}^{-1}$ $K_{\mathrm{dp}}$ along the leading edge of the convection just upstream from the broad, rotating portions of the convection and lesser $K_{\mathrm{dp}}$ values $\left(0.5^{\circ}-2^{\circ} \mathrm{km}^{-1}\right)$ are seen in the nonrotating regions (cf. Figs. 9-11c,g,k,o and Figs. 9-11d,h,i,p). The highest values of $K_{\mathrm{dp}}$, in the $4^{\circ}-5+{ }^{\circ} \mathrm{km}^{-1}$ range, are present within this broad $K_{\mathrm{dp}}$ structure and are spatially associated with the upstream regions of most intense rotation (cf. Figs. 911c,g,k,o and Figs. 9-11d,h,i,p), as in the first period of extreme rainfall. The spatial coverage of the $3+{ }^{\circ} \mathrm{km}^{-1}$ $K_{\mathrm{dp}}$ values on the leading convective edge appear to increase as the rotation intensifies and broadens over the period (cf. Figs. 9 and 10c,g,k,o and Figs. 9 and $10 \mathrm{~d}, \mathrm{~h}, \mathrm{i}, \mathrm{p})$. Furthermore, the most intense values of $K_{\mathrm{dp}}$ (i.e., $4^{\circ}-5+{ }^{\circ} \mathrm{km}^{-1}$ ) within the broader $K_{\mathrm{dp}}$ structure appear to intensify/are maintained as the spatially associated upstream regions of most intense rotation also intensify/are maintained (cf. Figs. 9 and 10c,g,k,o and 

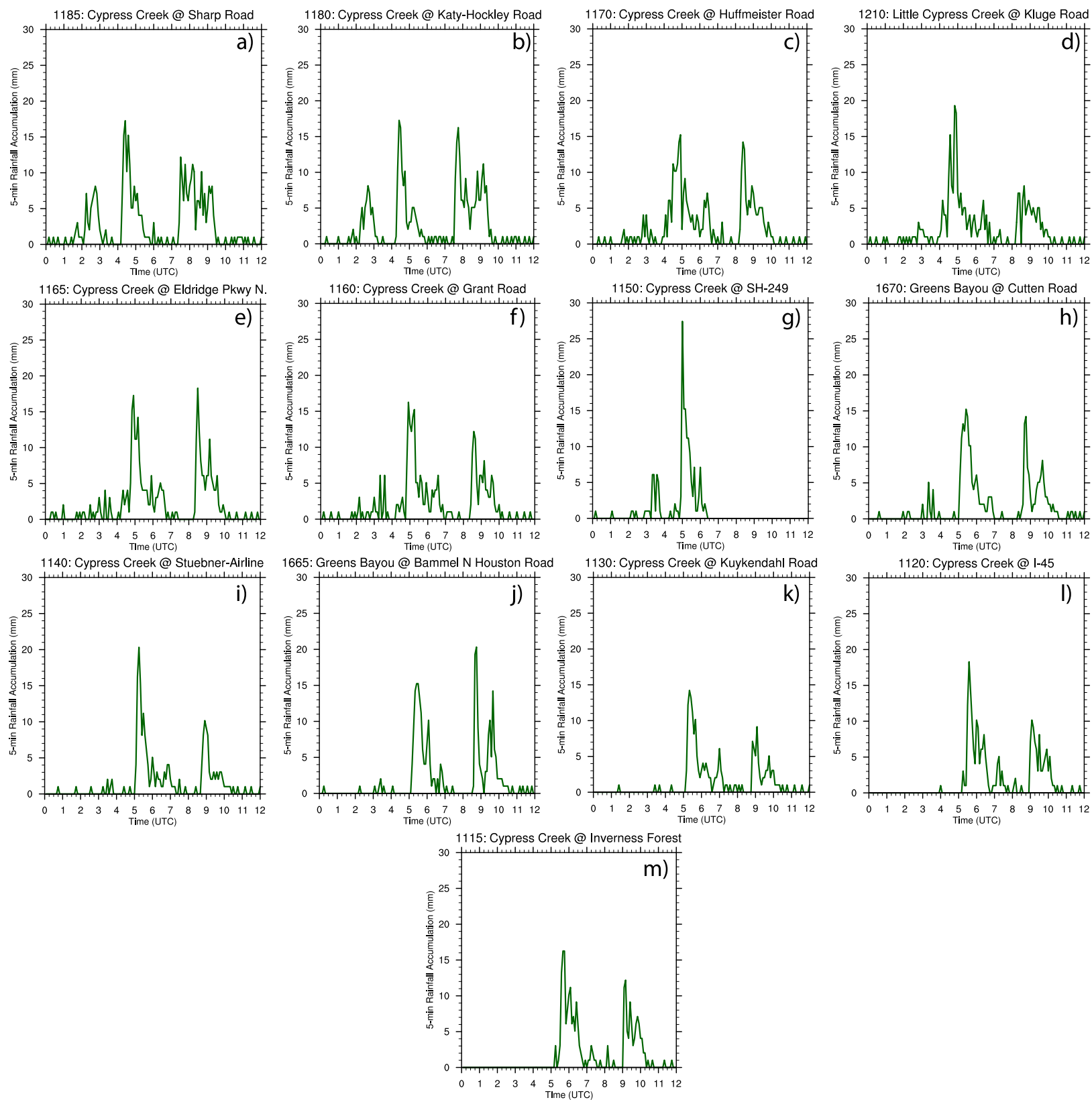

FIG. 7. Time series of 5-min rainfall accumulations from 13 HCFWS gauges valid 0000 UTC to 1200 UTC 18 Apr 2016 . Gauge locations are noted in Figs. 8, 9, 10, and 11 by large white markers with letters corresponding to the panel labels in this figure. (d) is missing data between 0725 and 810 UTC. (g) is missing data after 0620 UTC.

Figs. 9 and 10d,h,i,p). Both of these tendencies are illustrated well in 0808 to 0836 UTC time frame (Figs. 10c,d,g,h,k,l,o,p), as the rotation reaches its maximum. The local maxima and overall breadth of the $K_{\mathrm{dp}}$ structure strengthens/weakens as the rotation strengthens/weakens (Figs. 11c, d, g,h,k,l,o,p). However, there appears to be a slight lag in the $K_{\mathrm{dp}}$ weakening, when referenced to the timing of rotational weakening (Figs. 11c,d,g,h,k,l,o,p).
The rain gauge data in this second period of intense rainfall shows, as the radar data, a very similar pattern to the first period. The rainfall rates produced in high, $3+{ }^{\circ} \mathrm{km}^{-1} K_{\mathrm{dp}}$ regions associated with the rotating leading edge of the convection produce extreme 5-min rainfall accumulations, followed by smaller, but still substantial, 5-min rainfall rates after the highest $K_{\text {dp }}$ structures pass (Fig. 7). Examples can be seen in gauges across the 0700 to 0900 UTC time frame as the 

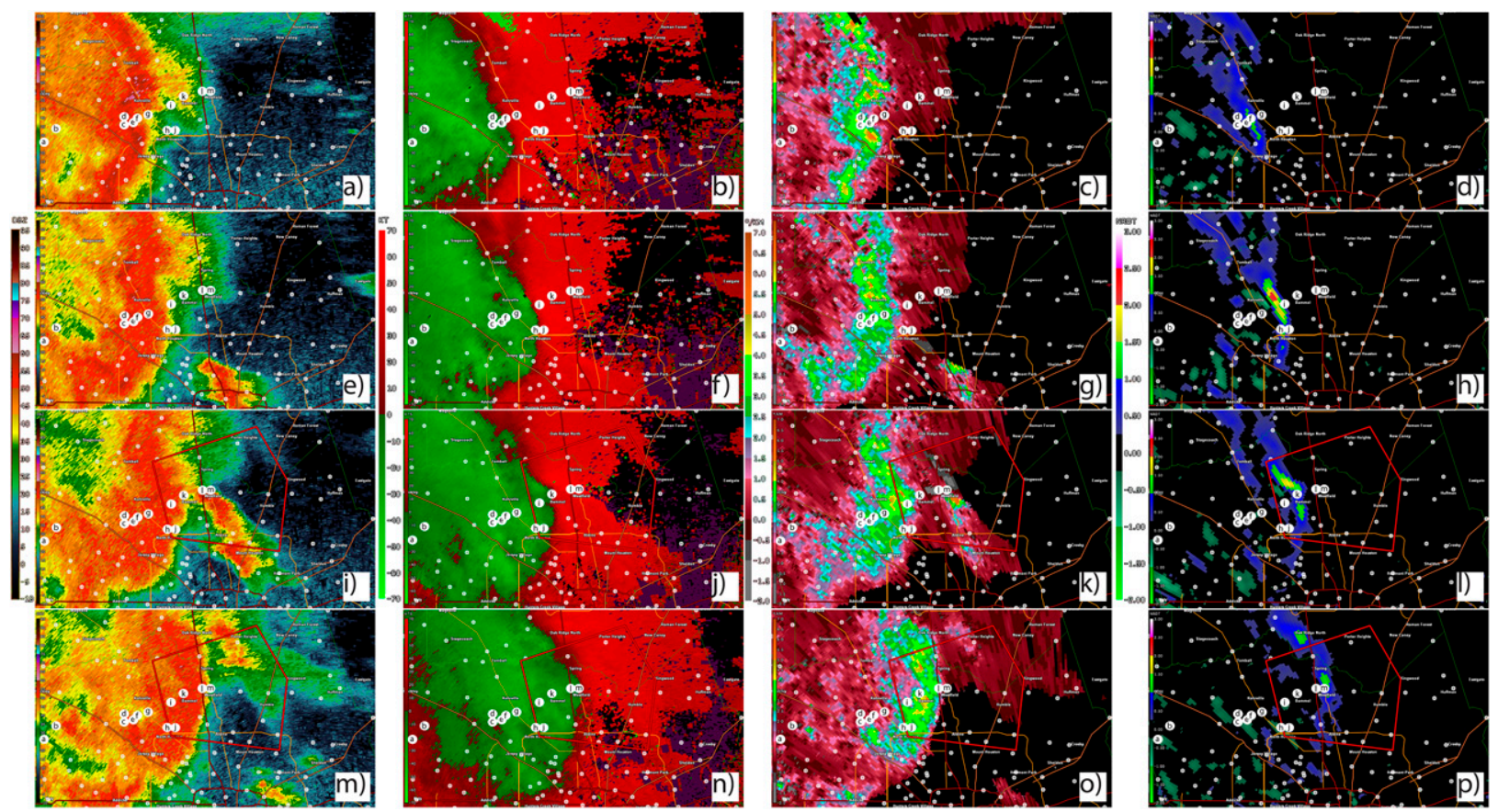

FIG. 8. (first column) Base radar reflectivity, (second column) radial velocity, (third column) specific differential phase $\left(K_{\mathrm{dp}}\right)$, and (fourth column) normalized rotation (NROT) as calculated by the Gibson Ridge GRLevel2 Analyst software (http://www.grlevelx.com/ gr2analyst/) from the Houston/Galveston NEXRAD radar (KGHX) valid at (a)-(d) 0445, (e)-(h) 0459, (i)-(l) 0510, and (m)-(p) 0528 UTC 18 Apr 2016. Small white markers correspond to locations of rain gauges as part of the Harris County Flood Warning System (HCFWS). Red polygons correspond to valid tornado warnings. Large white markers indicate the locations of the gauges presented in Fig. 7, where the letter on the marker corresponds to the panel label in Fig. 7 showing each respective gauges time series.

convection moves off to the east (Fig. 7). For instance, gauge B (Fig. 7b) in the early part of the period received $42.7 \mathrm{~mm}$ in the $15-\mathrm{min}$ period $\left(\sim 171 \mathrm{~mm} \mathrm{~h}^{-1}\right)$ beginning at 0735 UTC, which corresponds well to the period over which $K_{\mathrm{dp}}$ values near $4^{\circ} \mathrm{km}^{-1}$ were over the gauge location (Figs. 9g,k,o). However, 60 $120 \mathrm{~mm} \mathrm{~h}^{-1}$ rain rates at a 5 -min time scale are still observed following the passage of this high $K_{\mathrm{dp}}$ region. As the rotating feature continues to move east over the period, similar patterns are seen at the remaining gauges with 15-min accumulations associated with $1^{\circ}-3^{\circ} \mathrm{km}^{-1} K_{\mathrm{dp}}$ ranging from $\sim 22.4$ to $\sim 34.5 \mathrm{~mm}\left(\sim 89.6-138 \mathrm{~mm} \mathrm{~h}^{-1}\right)$. Gauges that experienced enhanced $K_{\mathrm{dp}}$ values above $4^{\circ} \mathrm{km}^{-1}$ near more intense rotating elements received more intense accumulations over the same period. For example, gauges $\mathrm{J}$ (Fig. $7 \mathrm{j}$ ) and $\mathrm{H}$ (Fig. $7 \mathrm{~h}$ ) received $\sim 34.5 \mathrm{~mm}$ and $\sim 48.8 \mathrm{~mm}\left(\sim 138-195.2 \mathrm{~mm} \mathrm{~h}^{-1}\right)$, respectively, in the 0835 to 0850 UTC period (from Fig. 10o to Figs. 11c,g). While gauge I (Fig. 7I), which experience smaller $K_{\mathrm{dp}}$ values near $3^{\circ} \mathrm{km}^{-1}$ between 0845 and 0900 UTC (Fig. 11), received $\sim 27.4 \mathrm{~mm}$. Last, as the rotation and $K_{\mathrm{dp}}$ values weakened as the convective line moved east, the 5-min rainfall accumulation maximums also weakened (cf. Fig. 11 and
Figs. $7 \mathrm{i}, \mathrm{k}-\mathrm{m})$. These results, combine with those in the first period of intense rainfall, support the previously stated hypothesis that the most intense short-term rainfall rates observed by the high-density rain gauge network in the Houston metro area are seen in regions of locally intense $K_{\mathrm{dp}}\left(4+^{\circ} \mathrm{km}^{-1}\right)$ associated with embedded, rotating features. This association will be further examined by a numerical model analysis of the system.

\section{Results: Model analysis}

The high-resolution, 600-m nest initiated within the HRRRx (referred hereafter as "analysis simulation") produced a convective system similar to that observed during the Tax Day event (Fig. 12). As in the observed system, the initial isolated convection congealed into a linear MCS that moved eastward through the Houston metro area (cf. Fig. 6a and Fig. 12c) on 18 April 2016. The convection in the analysis simulation produced regional rainfall accumulations on a similar order to those observed by the Stage-IV analysis (i.e., broad regions of over $300 \mathrm{~mm}$, Figs. 1a,c), but also included an event maximum that was on the order of that observed by the HCFWS gauges (i.e., $\sim 600 \mathrm{~mm}$, Fig. 1c). 

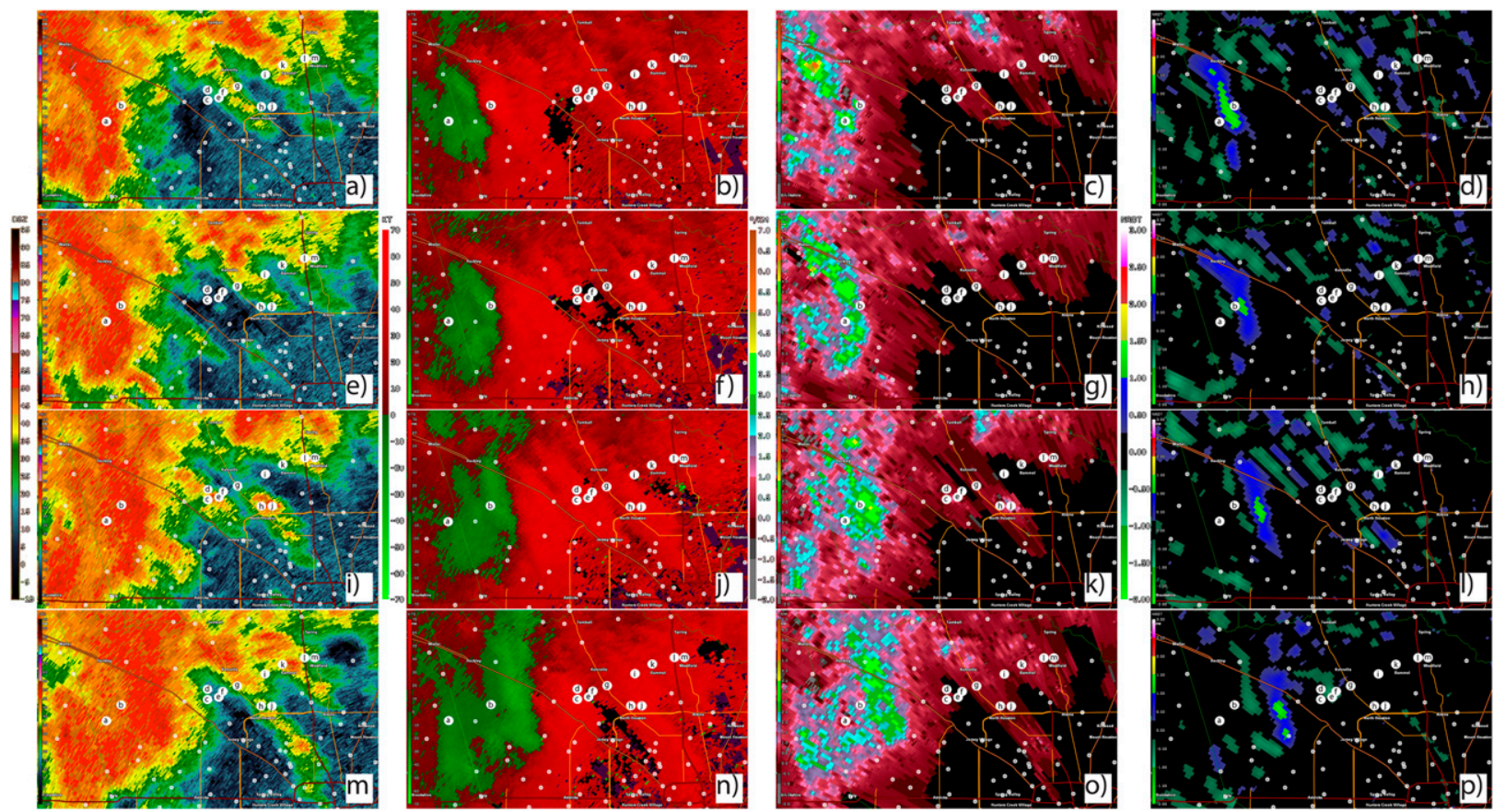

FIG. 9. As in Fig. 8, but valid at (a)-(d) 0726, (e)-(h) 0732, (i)-(1) 0739, and (m)-(p) 0749 UTC 18 Apr 2016.

Additionally, the analysis simulation produced significant rotation on various scales throughout the life cycle of the MCS (Fig. 12), including the development of supercells ahead of the convective line that eventually merge with the main body of convection (Figs. 12d-f). The presence of such features allows for further investigation of the rotational effects on this event.

Differences between the analysis simulation, observations, and, even, the HRRRx simulation that the analysis simulation was based on, do exist. The initial representation of the scattered convection at the start of the analysis simulation (Fig. 12a) was quite representative of observations (not shown). The convection in the simulation begins to congeal about the same time as seen in observations (between 0100 and 0200 UTC). However, the convection in the analysis simulation becomes more progressive and produces a larger north-south line of convection, compared to the observations, after the convection organizes into the convective line near 0430 UTC (cf. Fig. 6a and Fig. 12c). The increase in speed is seen by $\sim 0830$ UTC, as the main portion of the convective line in the analysis simulation is through downtown Houston (Fig. 12e), but not in the observations (Fig. 6b). This trend continues throughout the simulation. Last, the back-building that is seen in observations along the stationary outflow boundary edge toward San Antonio/Austin (Figs. 6b,c) is too far south in the analysis simulation (Figs. 12e-h).
The resulting differences in convective structure and speed between the observations and the analysis simulation, yield a precipitation swath that is more concentrated on the west side of Harris County in the analysis simulation compared to observations (Figs. 1a,c). There is also a lack of representation in the rainfall accumulations of the linear westward extension of convection toward San Antonio/Austin that was seen in observations (Figs. 1a,c) at the later times (Fig. 6c). These differences, combined with the increase in storm translation speed to the east in the analysis simulation, compared to both the observations and the HRRRx, leads to the bulk of heaviest rainfall amounts being seen south and east of where they were observed (Figs. 1a,c). While these differences are important, the presence of meso- $\gamma$-scale rotation and the ability for the analysis simulation to resolve the magnitude of the observed rainfall, allow the simulation to be used for analysis described above.

Soundings taken from the inflow region of the MCS in southern Fort Bend County, Texas, show kinematic and thermodynamic values (Fig. 13) similar to those discussed earlier based upon the RAP analysis (Figs. 3 and 4). MUCAPE vales near $1500 \mathrm{~J} \mathrm{~kg}^{-1}$ with a vertical structure similar to a flash flood profile (e.g., Davis 2001; Schumacher and Johnson 2009; Schroeder et al. 2016) were maintained throughout the simulation (Figs. 13a,b). Further, the soundings show the presence of intense $0-1 \mathrm{~km}$ shear that intensified 

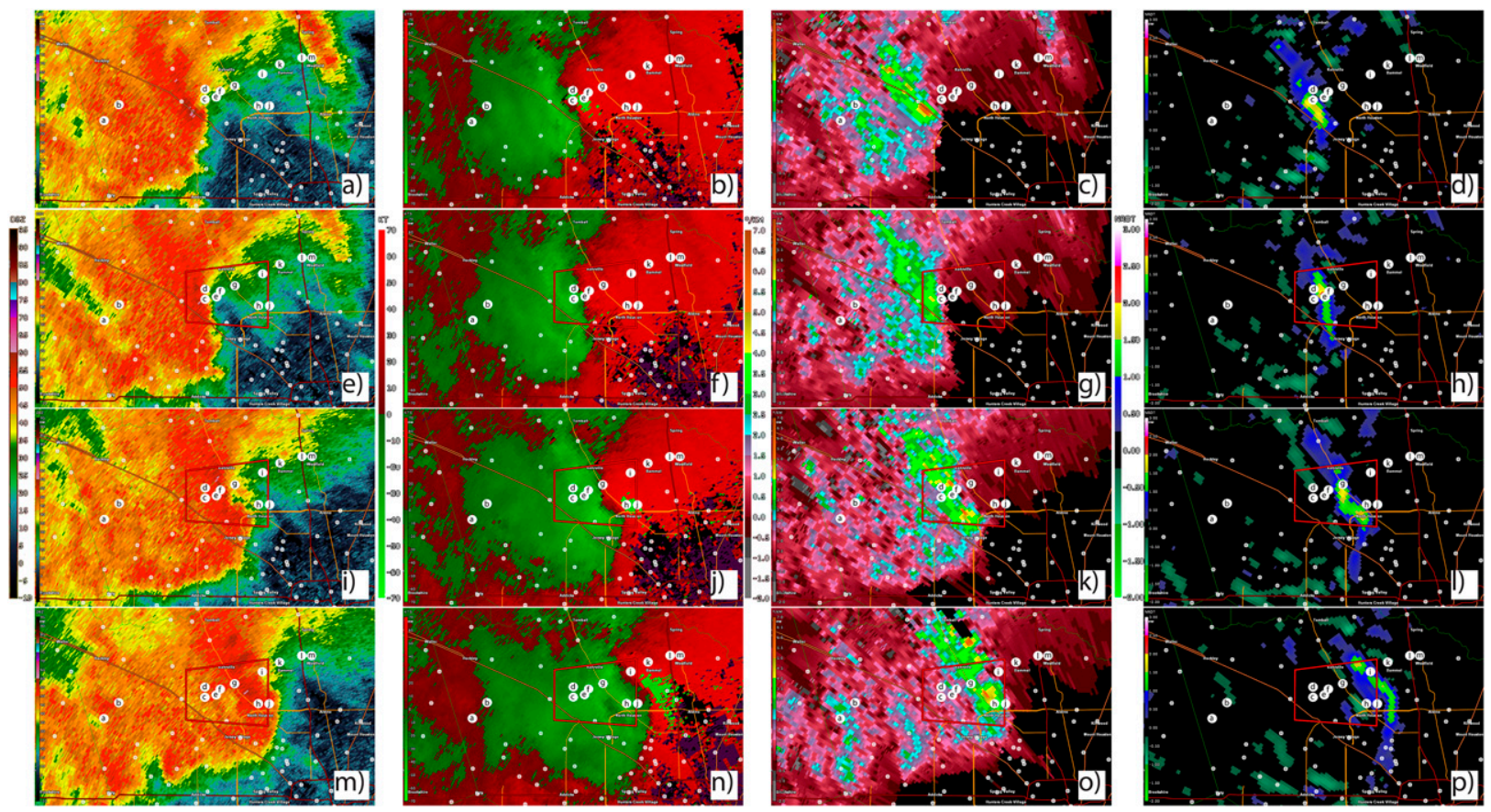

FIG. 10. As in Fig. 8, but valid at (a)-(d) 0808, (e)-(h) 0814, (i)-(l) 0825, and (m)-(p) 0836 UTC 18 Apr 2016

through the event to near $\sim 20 \mathrm{~m} \mathrm{~s}^{-1}$ (Fig. 13b). This was associated with $25+\mathrm{m} \mathrm{s}^{-1}$ southeasterlies in the $500 \mathrm{~m}$ to $1 \mathrm{~km}$ layer (Figs. 13a,b), and weak winds aloft associated with upper-level Omega blocking pattern. This created hodographs that were quite favorable for the development of rotating storms. The modeled $0-6 \mathrm{~km}$ shear does increase with time and is larger than what is originally represented in the SPC mesoscale analysis, which could be explained by the modification of the environment by convection. The surface parcel,
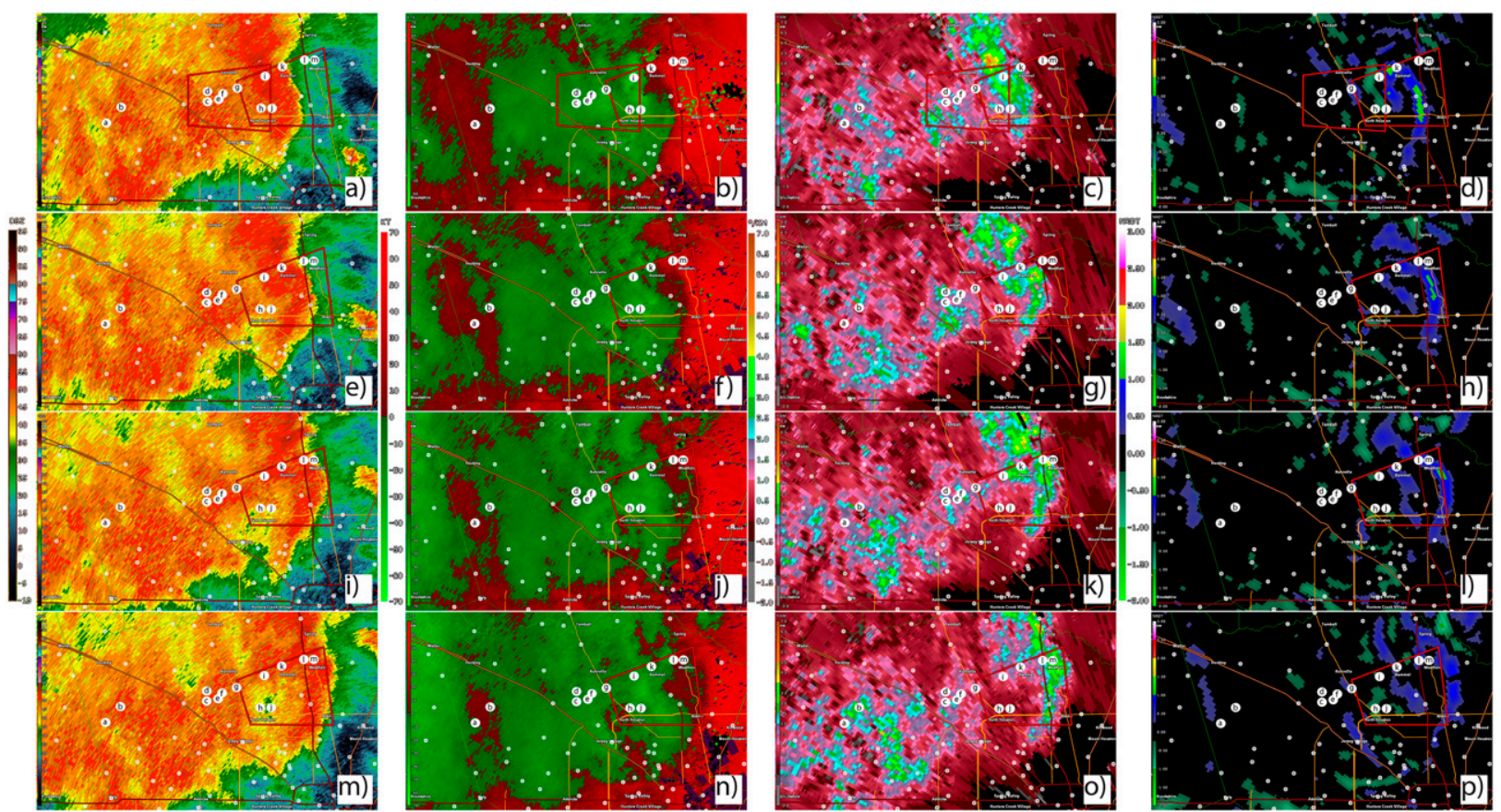

FIG. 11. As in Fig. 8, but valid at (a)-(d) 0844, (e)-(h) 0850, (i)-(l) 0855, and (m)-(p) 0900 UTC 18 Apr 2016. 

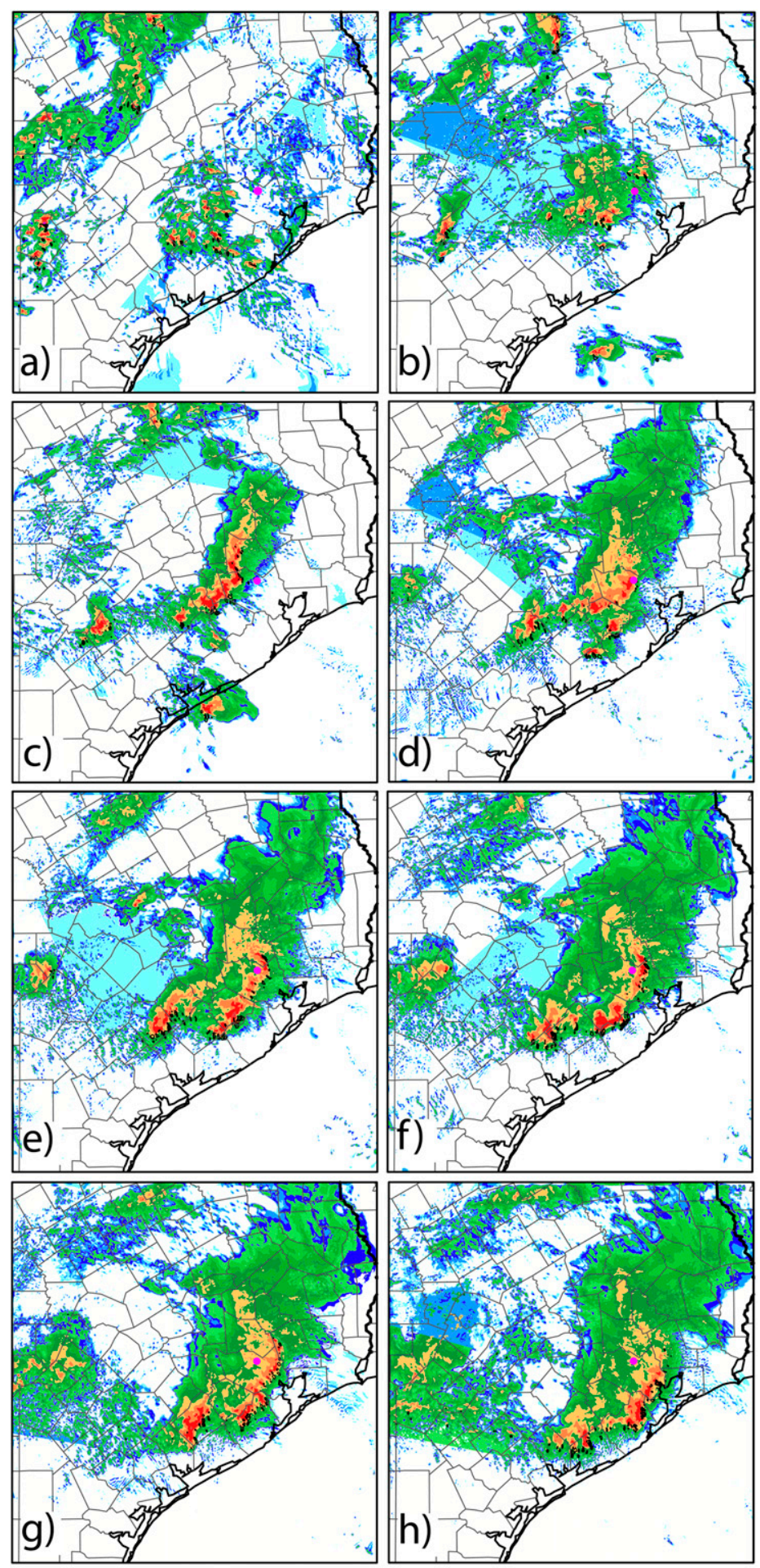

Radar reflectivity (lamda $=10 \mathrm{~cm})(\mathrm{dBZ})$

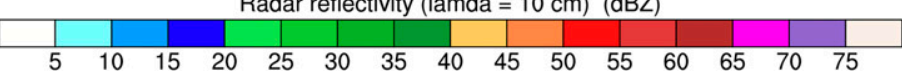

FIG. 12. Simulated 1-km radar reflectivity (fill; dBZ) and maximum updraft helicity (black contours; every $100 \mathrm{~m}^{2} \mathrm{~s}^{-2}$ starting at $150 \mathrm{~m}^{2} \mathrm{~s}^{-2}$ ) for the analysis domain valid (a) $30 \mathrm{~min}$, (b) $2 \mathrm{~h} 30 \mathrm{~min}$, (c) $4 \mathrm{~h} 30 \mathrm{~min}$, (d) $7 \mathrm{~h} 30 \mathrm{~min}$, (e) $8 \mathrm{~h}$ $30 \mathrm{~min}$, (f) $9 \mathrm{~h} 30 \mathrm{~min}$, (g) $10 \mathrm{~h} 30 \mathrm{~min}$, and (h) $11 \mathrm{~h} 30 \mathrm{~min}$ into the simulation initialized at 0000 UTC 18 Apr 2016. Magenta dot denotes the location of George H.W. Bush Intercontinental Airport (KIAH). 

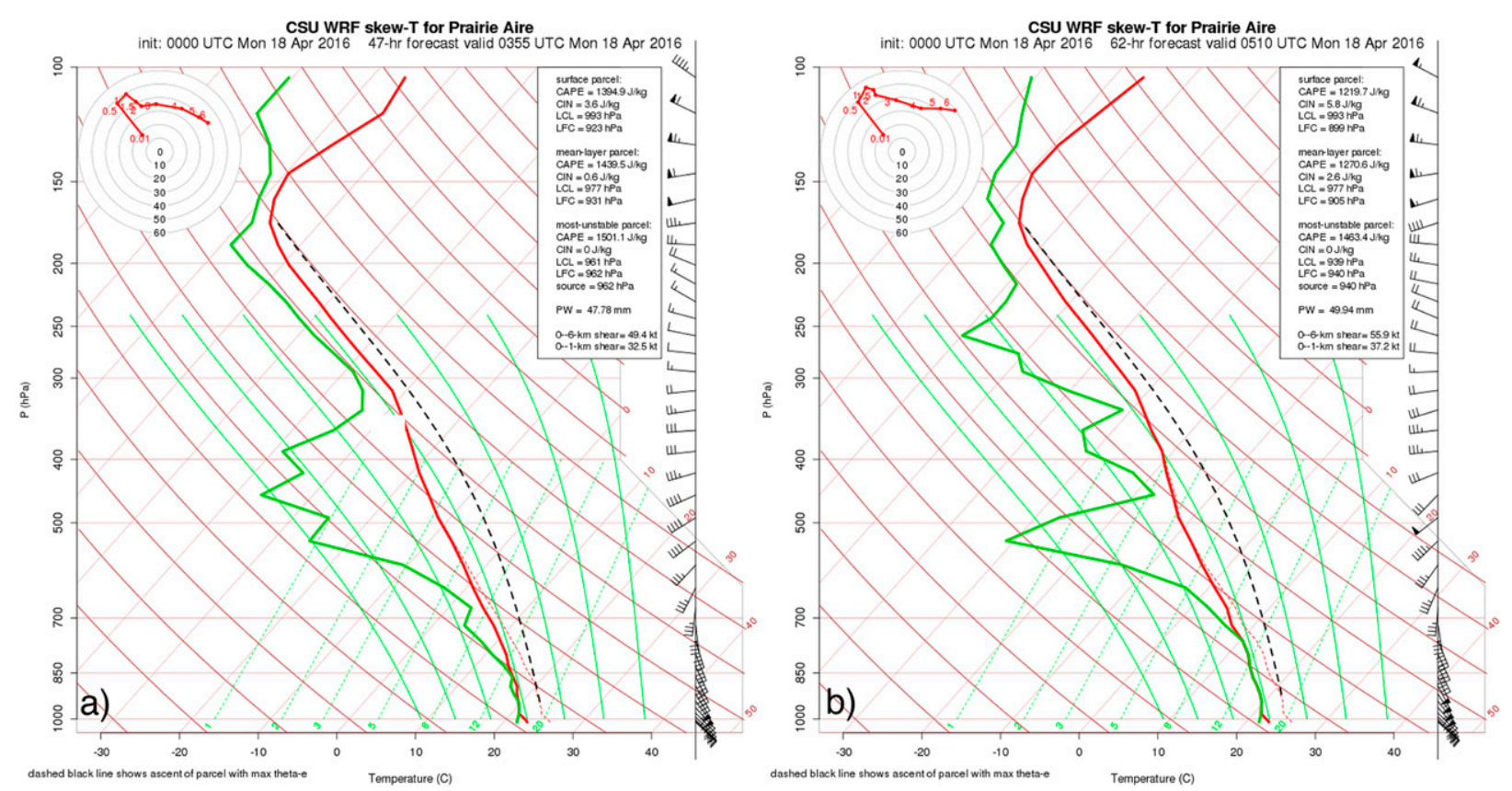

FIG. 13. Model soundings from the analysis domain valid at (a) $3 \mathrm{~h} 55 \mathrm{~min}$ and (b) $5 \mathrm{~h} 10 \mathrm{~min}$ into the 0000 UTC 18 Apr 2016 initialization from Prairie Aire Airfield (K4TAO) in southern Fort Bend County, Texas. Location denoted by blue $\times$ enclosed by a circle in Figs. 16 and 17 .

despite the significant moisture in the low levels, is still slightly stable. The most unstable parcel is uninhibited and has an origin near $950 \mathrm{hPa}$ (Figs. 13a,b). Additionally, PWAT in the model, as in the RAP analysis (Fig. 4a), lies between 45 and $50 \mathrm{~mm}$ throughout the analysis simulation.

Given the ability for rotating features to create extreme short-term rain rates in the radar analysis presented in the previous section, hourly precipitation accumulations and maximum updraft helicity (UH) were examined for a few select periods of the simulation. The first, between 0300 and 0600 UTC (approximately Figs. 12bd), was associated with the development of the main convective line and the formation/maintenance of several rotating features along the leading edge, similar to the two observed intense period of rainfall discussed in the previous section. The second, between 0700 and 1000 UTC (approximately Figs. 12d-g), was associated with the development ahead of and merger of supercells with the main convective line. Intense hourly accumulations were seen during both of these periods, with widespread regions of over $50 \mathrm{~mm}$ rainfall produced in the model (Fig. 14). Further, more localized, but still on the county spatial scale, regions of hourly accumulations between 100 and $\sim 150 \mathrm{~mm}$ were also seen in the model (Fig. 14). In the later period, the hourly maximum accumulations were over $200 \mathrm{~mm}$ (Figs. 14e,f). The maximum hourly accumulation observed by the HCFWS in the event was $120 \mathrm{~mm}$, which would imply that the upper threshold of the model simulation hourly accumulations might be an overestimation for this case. However, the analysis simulation rainfall values are still useful to compare between regions in the model.

The analysis simulation, as with the observed radar data, shows a spatial association between the highest rainfall accumulations and the regions of most intense UH (Fig. 14); further, the opposite is also true (i.e., lower accumulations in regions of weak/no rotation). The most intense accumulations are located north of the most intense rotating updrafts, which makes sense given the environmental kinematic profile for this simulation (Fig. 13). Additionally, this spatial association is seen both with rotation embedded in the convective line (Figs. 14a-c,f) and with isolated rotation features, in this case supercells, that develop out ahead of the main convection (Figs. 14d-e). This spatial association between maximum UH and the most intense hourly precipitation accumulations is seen during both periods, except at the northern part of the convection between 0400 and 0600 UTC, where the hourly maximum of hourly accumulation of $194 \mathrm{~mm}$ was recorded (Region enclosed by blue box in Fig. 14c). The lack of maximum updraft helicity in this region, compared to the other regions of large hourly rainfall accumulation, implies that either the updrafts are not rotating in the midlevel part of the storm (since this metric is calculated over the $2-5 \mathrm{~km}$ AGL layer in the model output) or the 

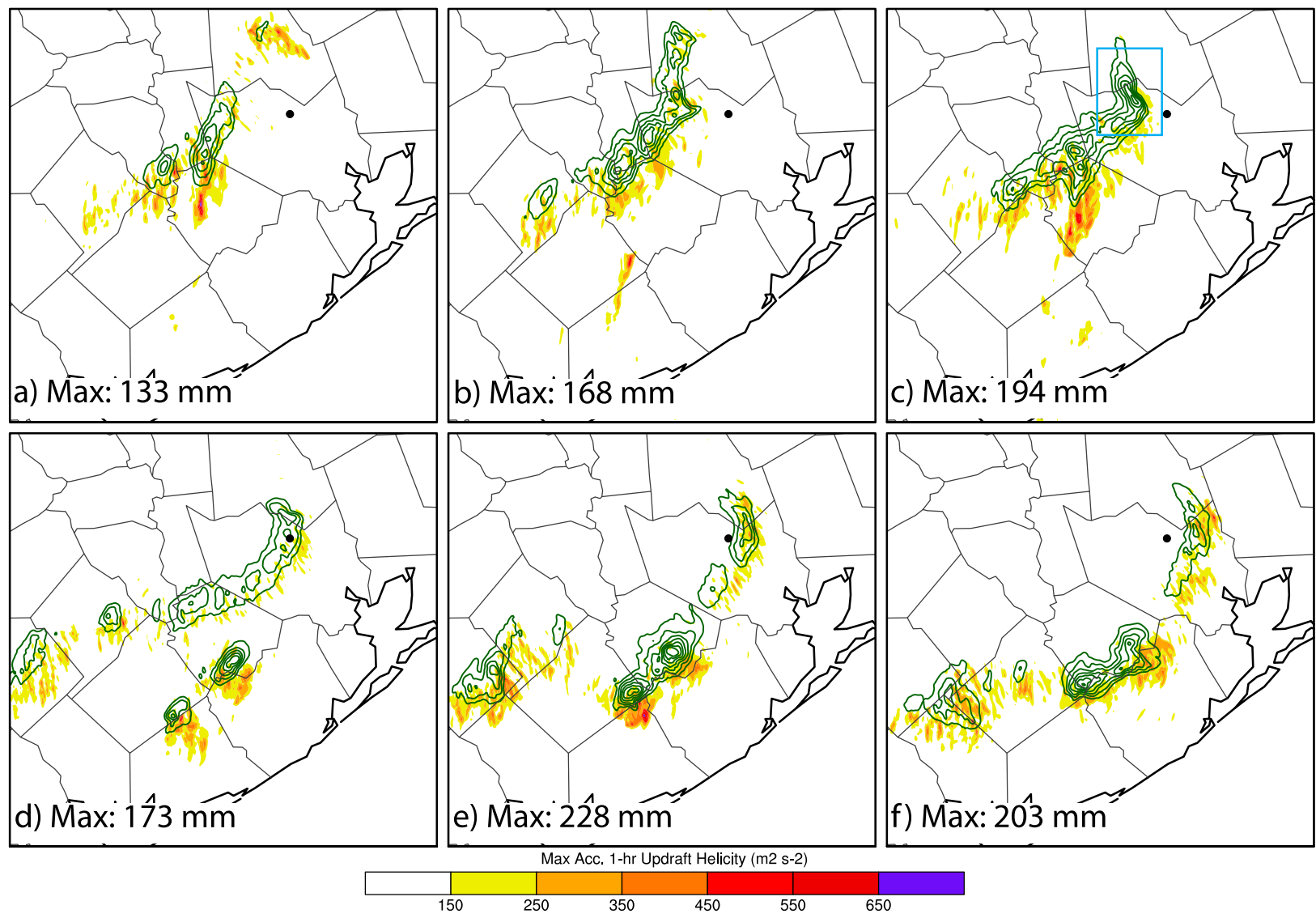

Max Acc. 1-hr Updraft Helicity (m2 s-2)

FIG. 14. 1-h maximum updraft helicity swaths (fill, $\mathrm{m}^{2} \mathrm{~s}^{-2}$ ) and 1-h precipitation accumulations (green contours; every $25 \mathrm{~mm}$ between 50 and $200 \mathrm{~mm}$ ) valid (a) $4 \mathrm{~h}$, (b) $5 \mathrm{~h}$, (c) $6 \mathrm{~h}$, (d) $8 \mathrm{~h}$, (e) $9 \mathrm{~h}$, and (f) $10 \mathrm{~h}$ into the 0000 UTC 18 Apr 2016 initialization for the analysis domain. Black dot denotes the location of George H.W. Bush Intercontinental Airport (KIAH). Maximum 1-h rainfall accumulations are marked on each panel. Blue box in (c) denotes region of interest discussed in section 5.

updrafts are not very strong. The latter of which seems unlikely, given the associated rainfall accumulation.

Examining these two periods of intense rainfall as events, as opposed to over predefined hours, continues to show a pattern of local UH maxima being located just upstream of the locally most intense rainfall accumulations (Figs. 15a,b). The exception still remains in the region at the northern extent of the convection line in the first period (region enclosed by blue box in Fig. 15a). In the low levels, a similar spatial association is seen between intense $1.5 \mathrm{~km}$ AGL vorticity and the regions of most-intense rainfall (Figs. 15c,d) for both events. Further, the maximum rainfall accumulation in the first period that previously was not associated with large maximum UH (i.e., blue box in Fig. 15a) is spatially related with intense values of low-level vorticity (i.e., $\sim 0.02 \mathrm{~s}^{-1}$, Fig. $15 \mathrm{c}$ ). This shows that the updrafts that produced the most intense rainfall accumulations in the analysis simulation are intensely rotating at the low levels, while only some are also rotating intensely at the midlevels. Additionally, the regions of maximum
$1.5 \mathrm{~km}$ vorticity correspond to the regions of $4+\mathrm{m} \mathrm{s}^{-1}$ updrafts at $500 \mathrm{~m}$ AGL over the same period (Figs. 15e,f), which is also spatially associated with regions of most intense rainfall accumulation. This implies that the strong updrafts at $500 \mathrm{~m}$ are associated with strong rotation at a slightly higher altitude and, presumably, influenced by the dynamical accelerations associated with that rotation. These bulk results agree with the idealized simulations in Nielsen and Schumacher (2018), which found that the enhancement of low-level (i.e., $500 \mathrm{~m}$ ) updrafts by the dynamical accelerations associated with rotation were the main mechanisms by which rain rates could be enhanced compared to nonrotating convection.

On the individual storm scale during both of these periods, comparable to the radar analysis in the previous section, a similar relationship between low-level rotation and intense rain rates is seen in the analysis simulation. At the beginning of the simulation (i.e., 40-min from initialization), when the convection was more isolated in nature, the most intense convection is associated with rotating features (Fig. 16a). It is also seen 
that the convection producing the most intense 5-min rainfall rates at the time are associated with these rotating portions of the system (Fig. 16e). This pattern continues as the system begins to organize into the linear convective mode that is seen through the end of the simulation (Fig. 16). During the first period discussed above (i.e., between 0300 and 0600 UTC), a spatial association is again seen at individual times between the embedded rotation features and the most intense short-term rainfall rates (Figs. 16b,f). The convection produces 5-min rainfall accumulations in the 5$10 \mathrm{~mm}$ range $\left(60-120 \mathrm{~mm} \mathrm{~h}^{-1}\right)$ throughout the convective line, but these values increase to the $15-25 \mathrm{~mm}$ range (180-300 $\left.\mathrm{mm} \mathrm{h}^{-1}\right)$ in the rotating regions (Fig. 16f). These modeled values are similar to those observed in nonrotating and rotating regions by the HCFWS gauges discussed in the previous section, respectively. The same spatial relationship between rotation and intense 5-min rainfall accumulations are seen in the second period described above (i.e., between 0700 and 1000 UTC) associated with supercellular convection (Figs. 16c,d,g,h). The 5-min rainfall accumulations in the $15-25 \mathrm{~mm}(180$ $300 \mathrm{~mm} \mathrm{~h}^{-1}$ ) range are modeled for the supercells, both when isolated ahead of and, embedded, in the main convective line (Figs. 16c,d,g,h).

Examining the $500 \mathrm{~m}$ vertical velocity and $1500 \mathrm{~m}$ vertical vorticity at the same individual times as presented in Fig. 16, the same relationship between the $500 \mathrm{~m}$ updraft strength, $1500 \mathrm{~m}$ vorticity, and modeled 5 -min rain rates is seen as in the aggregated temporal data in Fig. 15. The most intense rainfall rates are seen associated with convective cells that have the most intense vertical motion (i.e., $>2.5 \mathrm{~m} \mathrm{~s}^{-1}$ ) at $500 \mathrm{~m}$ (cf. fill colors in Figs. 17a-d and fill colors in Figs. 17e-h). The regions that sustain $>2.5 \mathrm{~m} \mathrm{~s}^{-1}$ updrafts at $500 \mathrm{~m}$ are almost exclusively associated with rotation at $1.5 \mathrm{~km}$ AGL (cf. fill and black contours in Figs. 17e-h), which can be seen throughout the simulation (Figs. 17e-h). Vertical motion at $500 \mathrm{~m}$ does exist outside of the regions of rotation along the cold pool boundary, but these values are weaker and associated with weaker 5-min rainfall totals (see blue line in Figs. 17f-h).

By following a specific region of low-level rotation in the vertical (denoted by area enclosed by blue box in Figs. 17b,f), the life cycle of the rotation and its effect on the system updraft structure and rainfall production can be seen. Initially as the low-level rotation begins to develop, it is confined to the lowest $2 \mathrm{~km}$ and little change in the overall structure of the storm is seen (see annotations in Fig. 18a). Additionally, the rainwater production at this time is associated with the elevated midlevel updraft (Fig. 18a). As the low-level rotation intensifies, a more clear lowering and enhancement of the low-level updrafts, compared to those not associated with rotation, is seen (Fig. 18c). A $4+\mathrm{m} \mathrm{s}^{-1}$ mean updraft over the cross-section area is seen below $1 \mathrm{~km}$ AGL in the center of the rotation (Fig. 18c), with little to no reduction in this value above the level of maximum rotation in the updraft core.

The vertical depth and strength of the low-level rotation increases as the vortex continues to move east (Figs. 18e,f). A broad lowering of the updraft base is still seen, corresponding to the region of low-level rotation, under a further developed midlevel updraft (Fig. 18e). Additionally, a clearly defined region of rainwater has now formed below the freezing level (green contours in Fig. 18e). Higher values of rainwater mixing ratio are seen at lower altitudes in the regions associated with low-level rotation, compared to regions of similar midlevel updraft strength without low-level rotation (Fig. 18e). This could imply more rainwater is being created in the low-level rotation regions compared to nonrotating low-level regions. Furthermore, the updraft enhancement and lowering is still maintained in the regions of low-level rotation, despite the increased hydrometeor loading associated with these increased rainwater mixing ratio values (Figs. 18e,g), which likely further speaks to the effects of the dynamical forcing associated with the rotation. These trends continue as the mean midlevel updraft continues to intensify, even though there is little change in the strength of the low-level rotation (Figs. 18g,h).

As the low-level rotation for this particular region of the storm reaches its local temporal maximum, a marked lowering of the updraft base combine with a large increase in low-level updraft strength is seen within the low-level rotation (Figs. 19a,b). This also corresponds to the period of most intense midlevel updraft strength and vertical alignment between the midlevel updraft and low-level rotation (Fig. 19a), which likely aided in the intensification of the low-level rotation (i.e., by stretching). Rainwater mixing ratios are, again, enhanced at lower altitudes in the region of low-level rotation, which corresponds to the most intense low-level updrafts (Fig. 19a). This is even true at the edges of the low-level rotation that are vertically aligned with the fringes of the midlevel updraft (north side of green contours in Fig. 19a). The low-level updrafts in the rotation region are still positive, despite the hydrometeor loading, and are just to the north of the main precipitation shaft (Fig. 19a).

A short time later, the region of low-level rotation is now collocated with the main precipitation shaft and downward motion, likely associated with a significant increase in hydrometeor loading (Figs. 19c,d), dominates. This period shows a substantial increase in total 

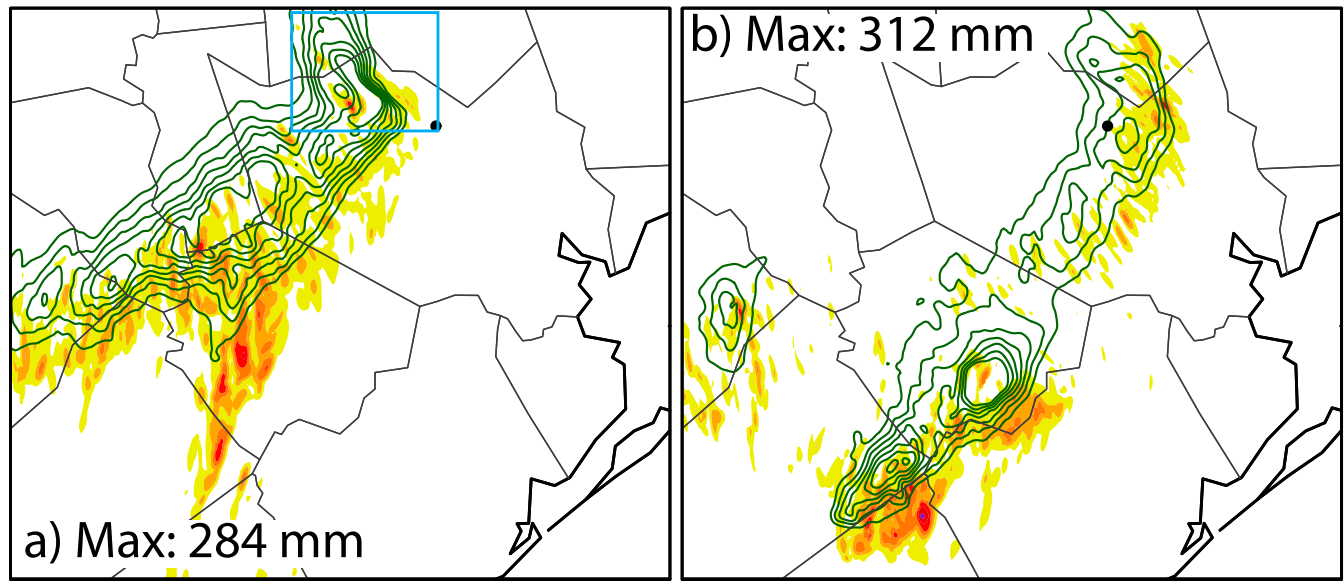

Max Acc. UH (m2 s-2)

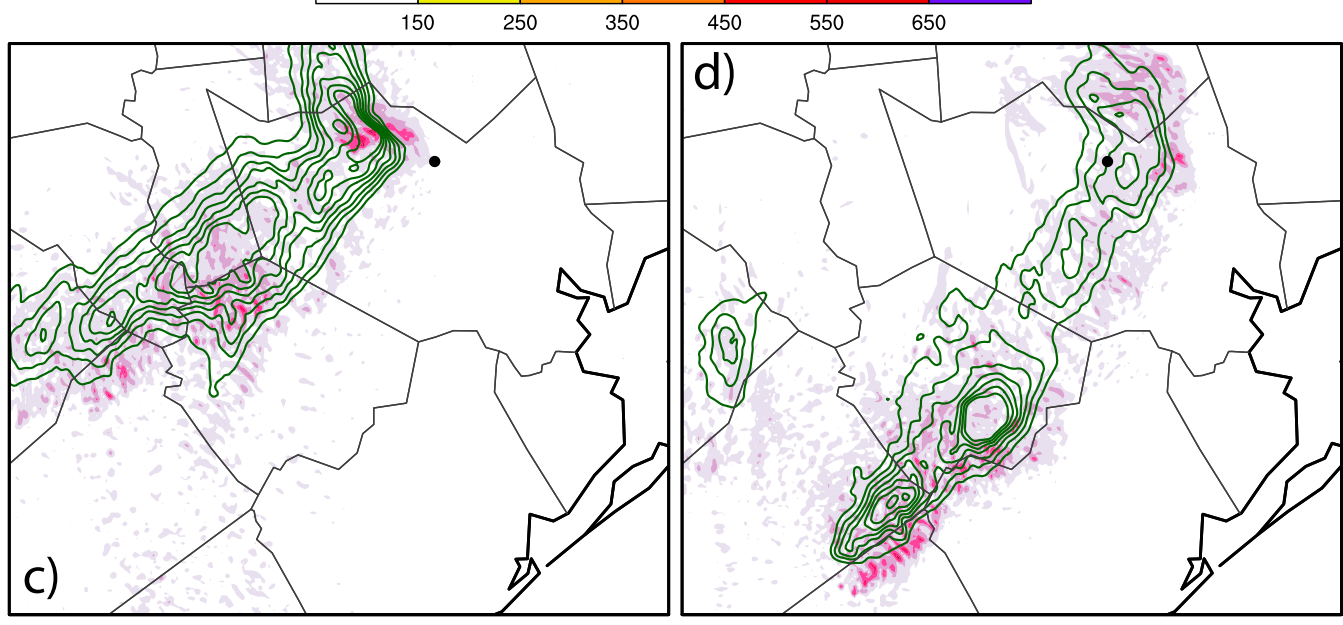

Max Vorticity Swath (x10-5 s-1)

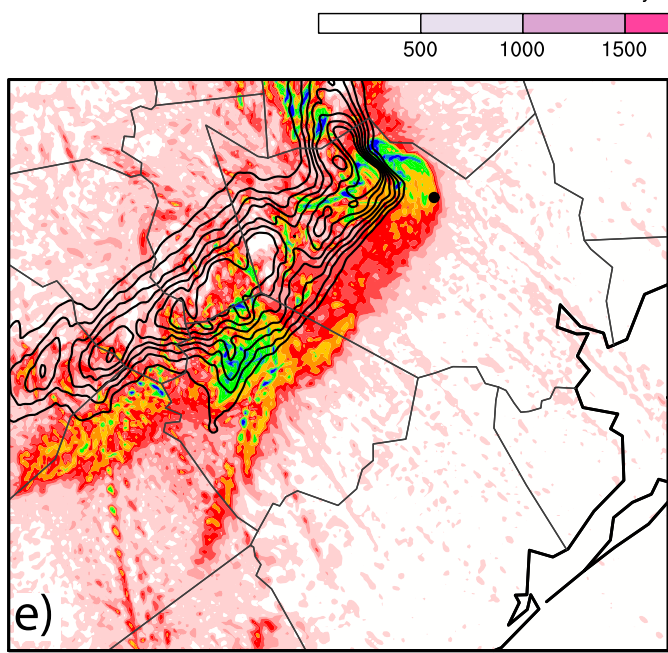

$2000 \quad 2500 \quad 3000$

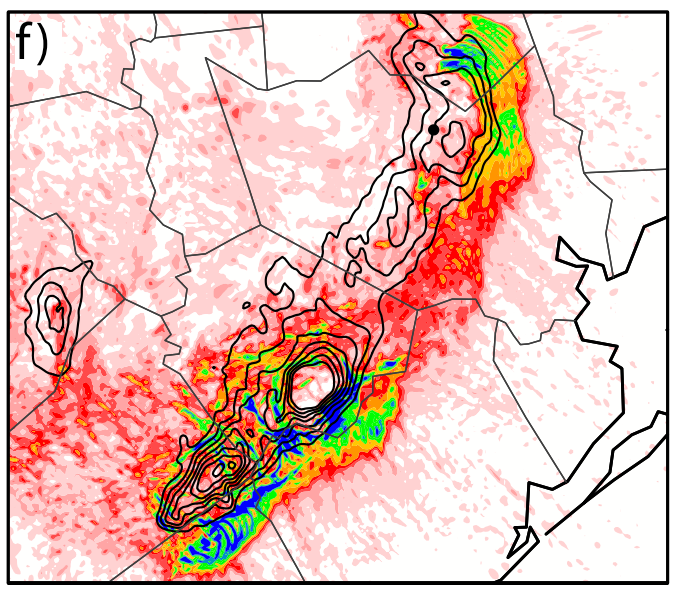

Max W Swath $(\mathrm{m} / \mathrm{s})$

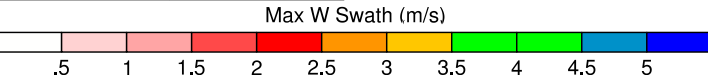

FIG. 15. Maximum updraft helicity swaths (fill, $\mathrm{m}^{2} \mathrm{~s}^{-2}$ ) and precipitation accumulations (green contours; every $25 \mathrm{~mm}$ between 50 and $200 \mathrm{~mm}$ ) valid for the (a) the period between 0430 and 0620 UTC and (b) the $90 \mathrm{~min}$ between 0730 and 0900 UTC of the 0000 UTC 18 Apr 2016 initialization over the analysis domain. Maximum rainfall accumulations over each period are marked in (a),(b). (c),(d) As in (a),(b), respectively, but the fill now represents swaths of maximum vorticity $\left(\times 10^{-5} \mathrm{~s}^{-1}\right)$ at $1.5 \mathrm{~km}$ above ground level. (e),(f) As in (a),(b), 

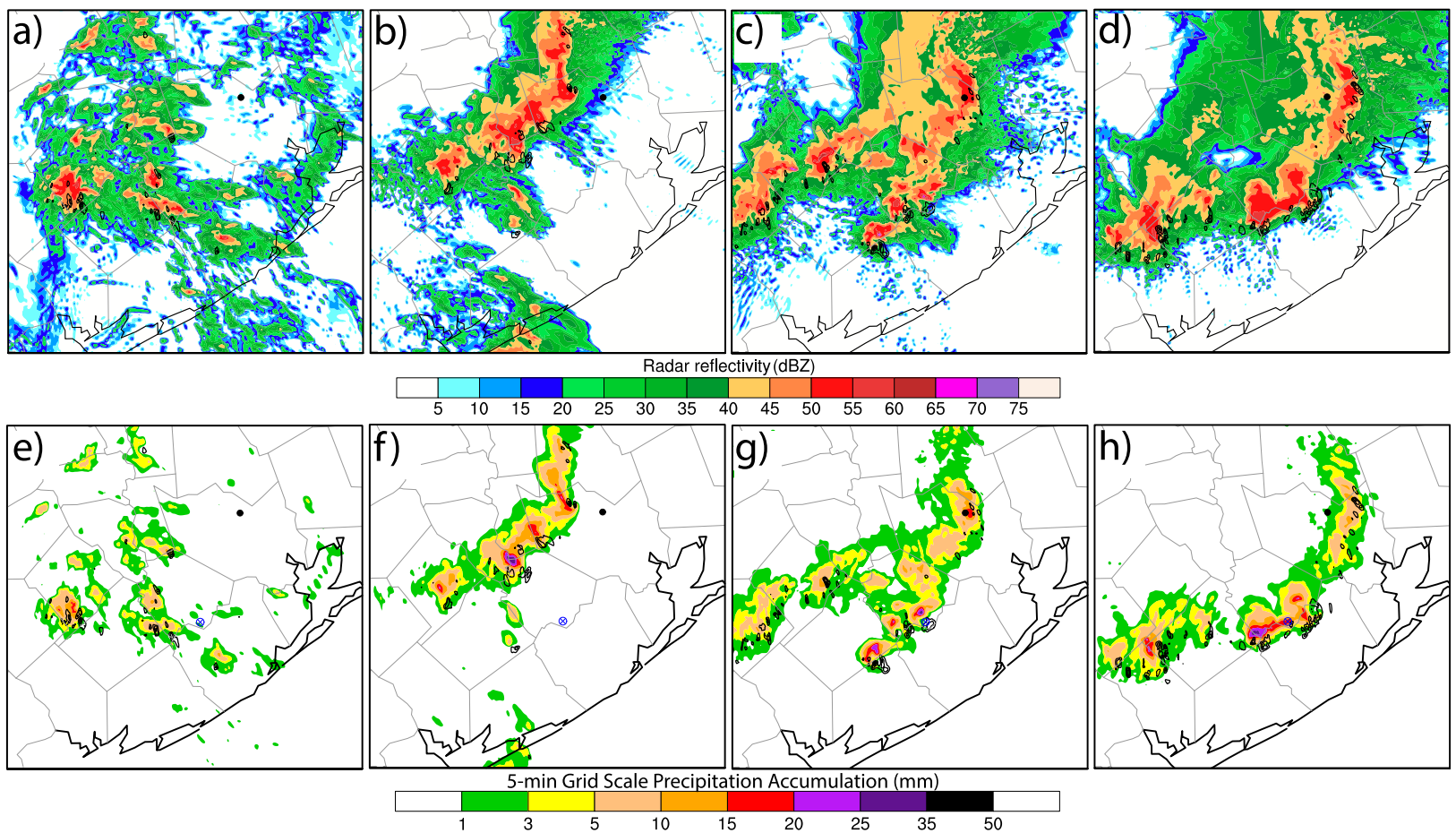

FIG. 16. (a)-(d) Simulated 1-km radar reflectivity (fill; dBZ) and maximum updraft helicity (black contours; every $100 \mathrm{~m}^{2} \mathrm{~s}^{-2}$ starting at $150 \mathrm{~m}^{2} \mathrm{~s}^{-2}$ ). (e)-(h) 5-min accumulated precipitation (fill, mm) and maximum updraft helicity (black contours; every $100 \mathrm{~m}^{2} \mathrm{~s}^{-2}$ starting at $150 \mathrm{~m}^{2} \mathrm{~s}^{-2}$ ). Panels show a zoomed-in subset of the analysis domain valid (a), (e) $40 \mathrm{~min}$, (b), (f) $4 \mathrm{~h} 40 \mathrm{~min}$, (c),(g) $7 \mathrm{~h} 55 \mathrm{~min}$, and (d),(h) $9 \mathrm{~h} 30$ min into the simulation initialized at 0000 UTC $18 \mathrm{Apr} 2016$. Black dot in all panel denotes the location of George H.W. Bush Intercontinental Airport (KIAH). Blue $\times$ enclosed by circle in bottom panels denotes location of Prairie Aire Airfield (K4TAO).

rainwater mixing ratio, compared to 15 min earlier (Figs. 19a,b), when the low-level rotation, low-level updraft, and midlevel updraft were maximized. Given that a lag between the surface rainfall magnitude and associated precipitation formation mechanisms is expected, this is not surprising. While low-level rotation is still present at this time, it has weakened and does not possess the same level or organization as seen previously (cf. Figs. 19a,c). The midlevel updraft has also weakened and become less organized (Fig. 19c). At this time the rainwater mixing ratios that are now reaching the surface undercut, to a degree, the storm inflow and disrupt the low-level rotation structure (Fig. 19c), which signals a restart of the precipitation life cycle of this particular cell.

As the rainfall at the surface decreases and narrow in areal coverage, the low-level rotation is able to reform
(Fig. 19e,f). Similarly to the previous time periods, a lowering and enhancement of the low-level updraft is seen in the low-level rotation (Fig. 19e). This in turn leads to increased rainwater mixing ratios at lower heights, compared to regions without the low-level updraft enhancement/rotation (Fig. 19e). As the midand low-level updrafts become vertically aligned, the low-level rotation shows signs of enhancement and extends farther into the midlevels (Fig. 19g), similar to what was seen earlier (Fig. 19a). The increase in updraft strength, lowering of the updraft base, and increase in rainwater mixing ratios are again seen in the region of low-level rotation (Fig. 19g), despite the largest rainwater mixing ratio values seen to this point. Further, the enhancement in rainwater mixing ratio is increased from (Fig. 19e) to (Fig. 19g), as the low-level rotation strengthens. The reformation of

respectively, but the fill now represents swaths of maximum $500 \mathrm{~m}$ AGL vertical velocity $\left(\mathrm{m} \mathrm{s}^{-1}\right)$ and precipitation contours are now in black. Black dot denotes the location of George H.W. Bush Intercontinental Airport (KIAH). Note spatial extent is zoomed in, compared to Fig. 14. Blue box in (a) denotes region of interest discussed in section 5. 

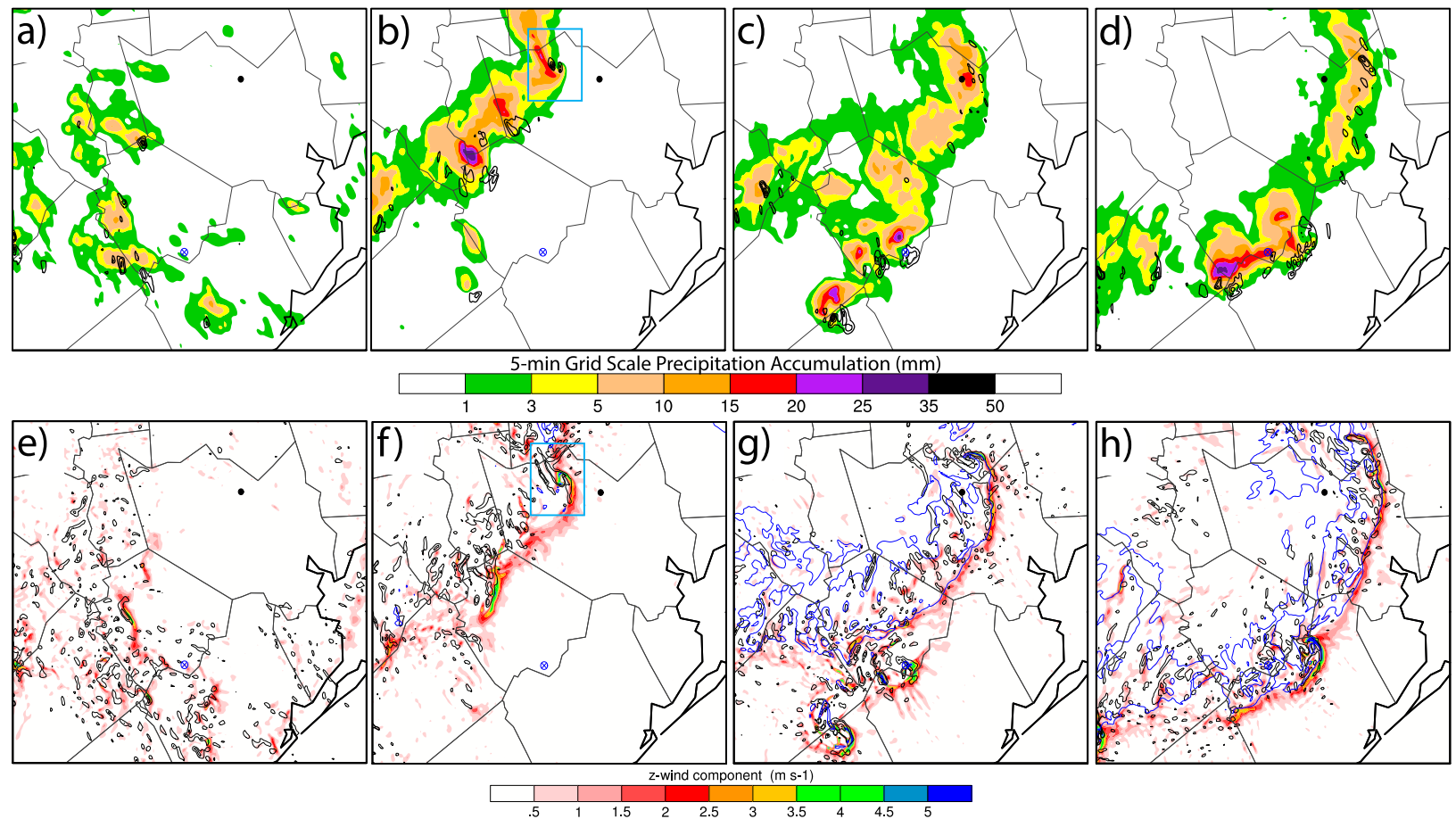

FIG. 17. (a)-(d) 5-min accumulated precipitation (fill, mm) and maximum updraft helicity (black contours; every $100 \mathrm{~m}^{2} \mathrm{~s}^{-2} \mathrm{starting}$ at $150 \mathrm{~m}^{2} \mathrm{~s}^{-2}$ ). (e)-(h) 500-m vertical velocity (fill, $\mathrm{m} \mathrm{s}^{-1}$ ), $1.5-\mathrm{km}$ vorticity (black dashed contours; at $0.003 \mathrm{~s}^{-1}$ and $0.008 \mathrm{~s}^{-1}$ ), and model perturbation potential temperature (blue contours at -5 and $-10 \mathrm{~K}$ ). Panels are valid at (a),(e) $40 \mathrm{~min},(\mathrm{~b}),(\mathrm{f}) 4 \mathrm{~h} 40 \mathrm{~min},(\mathrm{c}),(\mathrm{g}) 7 \mathrm{~h}$ $55 \mathrm{~min}$, and (d),(h) $9 \mathrm{~h} 30 \mathrm{~min}$ into the simulation initialized at 0000 UTC 18 Apr 2016, same as in Fig. 16. Note, however, spatial extent is further zoomed in than Fig. 16. Black dot in all panel denotes the location of George H.W. Bush Intercontinental Airport (KIAH). Blue $\times$ enclosed by circle in all panels denotes location of Prairie Aire Airfield (K4TAO). Blue box in (b) denotes region of interest discussed in section 5, and corresponds to same area in Fig. 15a.

the low-level rotation and the continuation of the same trends seen previously, imply that the life cycle and characteristics of these rotating, heavily precipitating regions are similar across the system and repeated as the storm system moves south and east through the simulation.

Examining the low-level pressure field for a select time from the above cross sections (Fig. 20), shows a vertical distribution of local pressure variations ${ }^{5}$ that aligns with the aforementioned ability for rotation to dynamically drive vertical motion. Local low pressure is seen within the rotating updrafts that is minimized

\footnotetext{
${ }^{5}$ The local pressure variations plotted in Fig. 20 are not true perturbations, as the numerical solving for the components of the pressure field in a full $3 \mathrm{D}$ simulation is nontrival. These fields are differences from the mean pressure field of each individual mean cross section at the corresponding vertical level. Thus, they show local pressure differences compared to the mean at that specific time seen across the plotted mean cross section at that level. The plotted differences therefore are not only due to the effects of rotation and have components included from many physical processes and the values cannot be compared across the cross sections.
}

near or slightly above the level of maximum rotation (Fig. 20), with increasing local pressure variations above this level. This makes sense, as the dynamic, nonlinear vertical pressure perturbation gradient is expected to reverse above the level of maximum rotation (see section 2.5.3 of Markowski and Richardson 2010). The negative pressure perturbations are maximized aloft and, thus, lead to upward directed acceleration in the low levels (Fig. 20). Additionally, the deeper the rotation, the deeper the pressure perturbations extend into the vertical in the simulation. The lowering and enhancement of the low-level updrafts that has been previously discussed in this section aligns with these rotating regions of local low pressure. No clear sign of the expected downward acceleration above the level of most intense rotation (i.e., where the vertical pressure gradient reverses) is seen in the net vertical motion field. This is likely to due to the added influence of thermodynamic buoyancy accelerations, as the levels of maximum rotation, and thus depth of positive vertical motion, all extend past the level of free convection (e.g., Fig. 13). Overall, the pressure field seems to support the notion that the dynamical effects of 

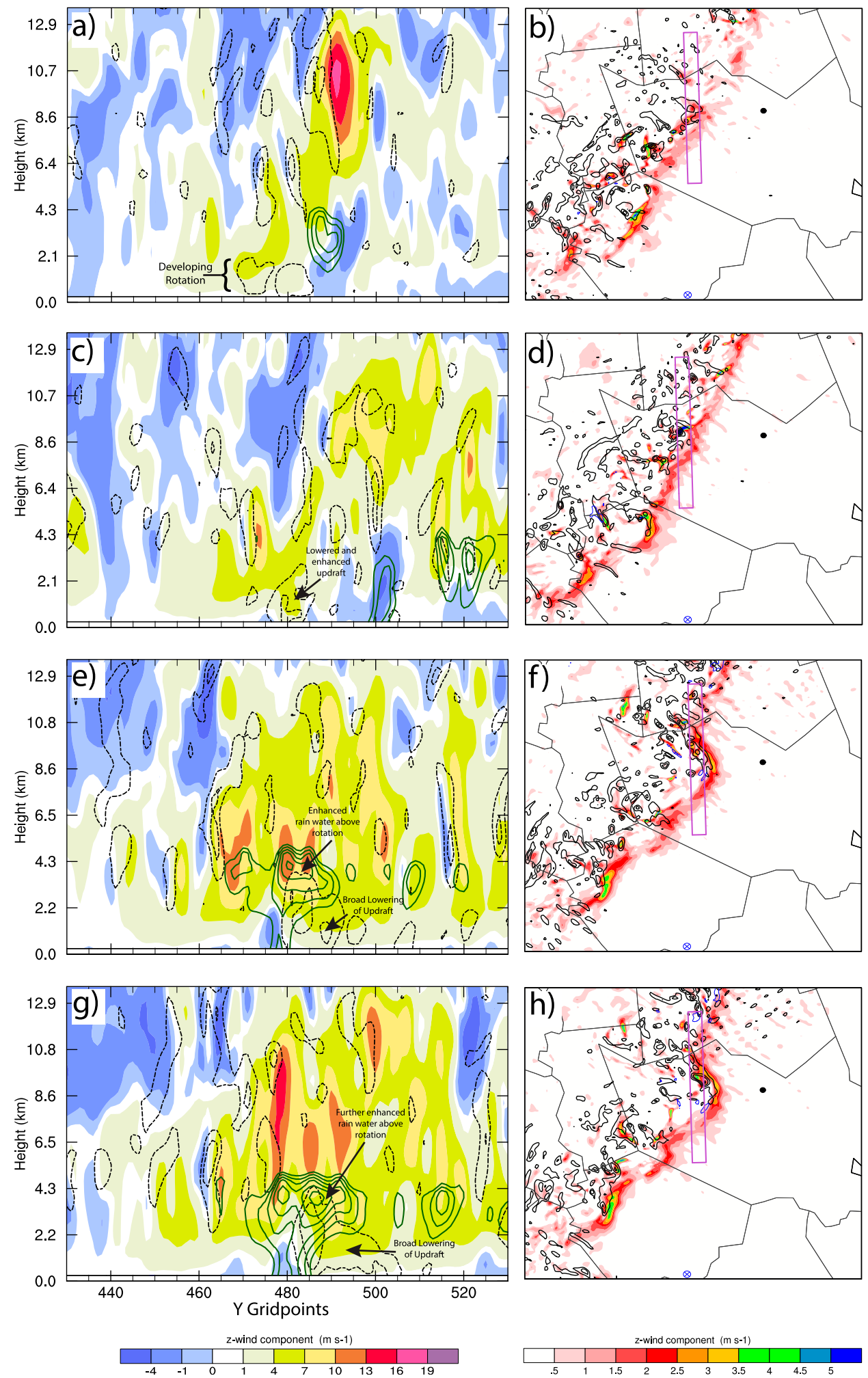

FIG. 18. (a),(c),(e),(g) Mean north-south vertical cross sections of vertical velocity (fill, $\mathrm{m} \mathrm{s}^{-1}$ ), vertical vorticity (dashed black contours, every $0.005 \mathrm{~s}^{-1}$ starting at $0.003 \mathrm{~s}^{-1}$ ), and rainwater mixing ratio (green contours, every $0.001 \mathrm{~kg} \mathrm{~kg}^{-1}$ starting at $0.004 \mathrm{~kg} \mathrm{~kg}^{-1}$ ) over the purple box shown in (b),(d),(f),(h) valid at (a),(b) 0335, (c),(d) 0350, (e),(f) 0425, and (g),(h) 0430 UTC 18 Apr 2016 from the analysis simulation. (b),(d),(f),(h) As in in Figs. 17e-h, but now valid at the aforementioned times. Black dot in all panel denotes the location of George H.W. Bush Intercontinental Airport (KIAH). Blue $\times$ enclosed by circle in all panels denotes location of Prairie Aire Airfield (K4TAO). 

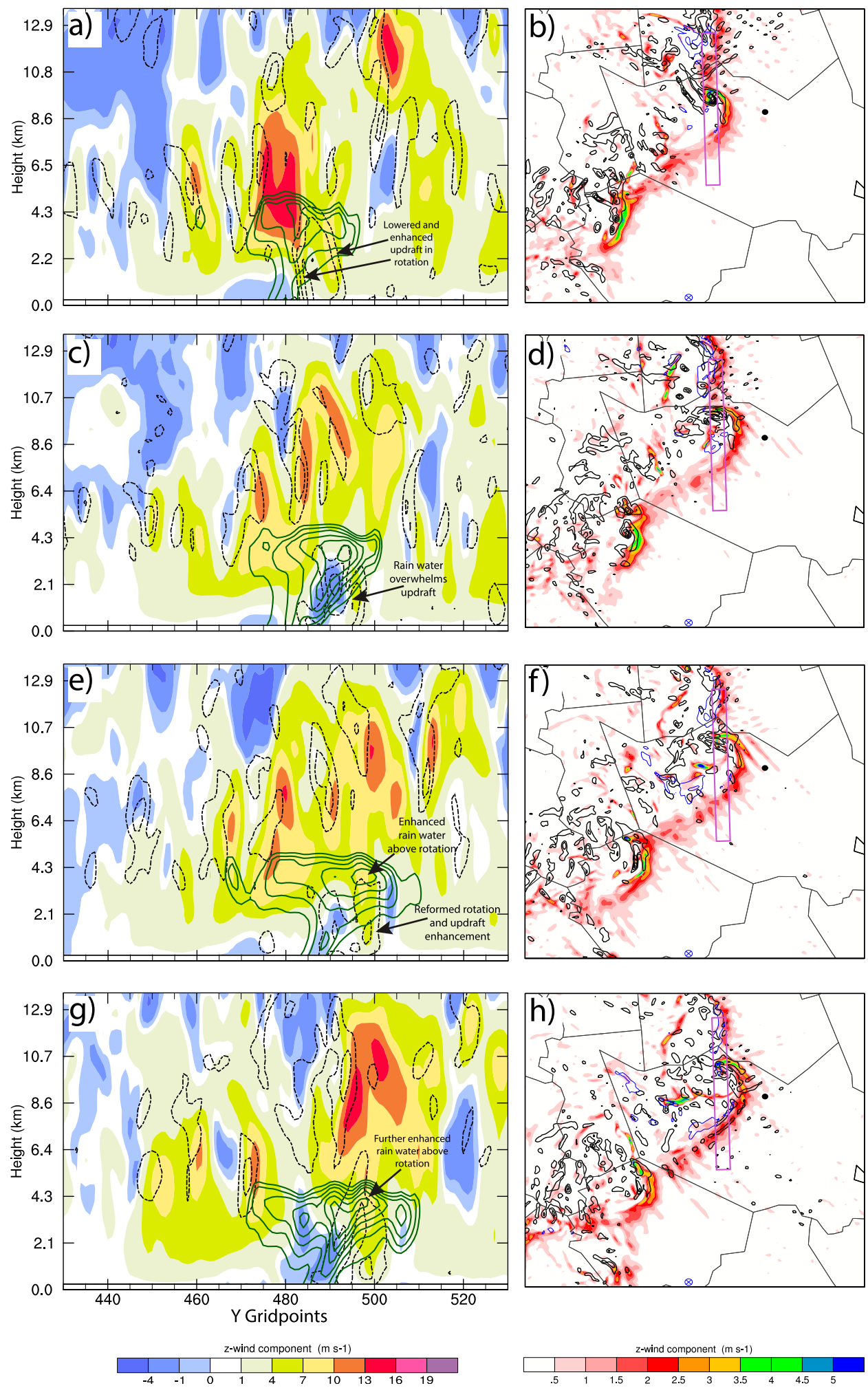

2-wind component ( $\mathrm{ms}-1$ )

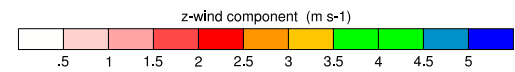

FIG. 19. As in Fig. 18, but valid at (a),(b) 0440, (c),(d) 0455, (e),(f) 0505, and (g),(h) 0515 UTC 18 Apr 2016 from the analysis simulation. 


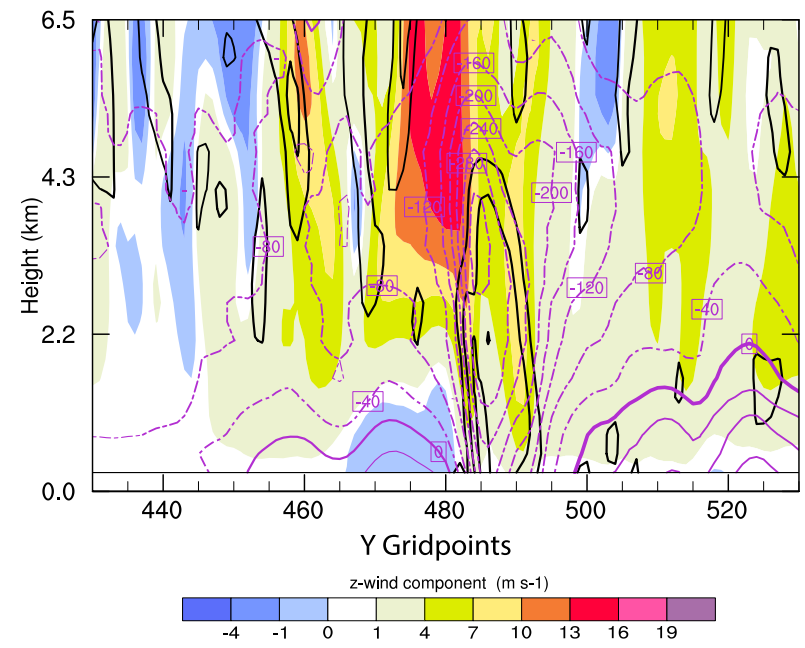

FIG. 20. As in Fig. 18, but valid at 0430 UTC 18 Apr 2016 from the analysis simulation focusing on the lowest $6.5 \mathrm{~km}$ of the cross section. The $1.5-\mathrm{km}$ vorticity is now in solid black contours at same interval as Fig. 18, and local pressure variations (see footnote 5) are plotted in the purple lines every $40 \mathrm{~Pa}$ with negative variations in the dashed lines, positive in the solid.

the rotation are responsible for the differences seen in the low-level vertical motion fields between the rotating and nonrotating regions of the system.

\section{Discussion and conclusions}

The results of the observational and model analyses both show that extreme rain rates during the Houston Tax Day flood were associated with regions of meso- $\gamma$-scale rotation in an intensely sheared low-level environment. The observational analysis, based upon radar and the HCFWS rain gauge network, showed that $15-25 \mathrm{~mm} 5$-min observed rain rates $\left(\sim 180-300 \mathrm{~mm} \mathrm{~h}^{-1}\right)$ were sustained over the course of the event just upstream of locally intense regions of low-level rotation (Fig. 7) and associated local enhancements of $K_{\mathrm{dp}}$ in the $4{ }^{\circ}-5+{ }^{\circ} \mathrm{km}^{-1}$ range. Intense 5-min rainfall rates $\left(\sim 60-120 \mathrm{~mm} \mathrm{~h}^{-1}\right)$ were seen throughout the nonrotating convective region that were associated with $K_{\mathrm{dp}}$ values in the $0.5^{\circ}-2^{\circ} \mathrm{km}^{-1}$ range, which is not surprising given how conducive the environment was to convection and rainfall (Fig. 13). The analysis simulation also produced similar 5-min rainfall accumulations as the observations in the most intensely rotating features, both in discrete and embedded convective cells (Fig. 15), and modeled nonrotating features. Overall, these results provide further evidence, similar to those presented in Nielsen and Schumacher (2018), that storms with meso- $\gamma$ scale can produce and maintain extreme rainfall rates, despite what is believed to be low-precipitation efficiency in some cases (e.g., Marwitz 1972; Foote and Fankhauser 1973; Browning 1977).

Nielsen and Schumacher (2018) showed that the presence of rotation associated with intense $0-1 \mathrm{~km}$ shear can serve to enhance rain rates, and overcome a presumed lack of precipitation efficiency, by providing a dynamical source of positive vertical momentum to the low-level updrafts that is not present in nonrotating storms [see section 2.5.3 of Markowski and Richardson (2010)]. Even though the dynamical accelerations associated with rotation were not explicitly solved for, evidence of the dynamics behind the rotational precipitation enhancement mechanism proposed in Nielsen and Schumacher (2018) are seen. The regions of most intense rainfall corresponded to regions of most intense low-level vertical velocity (i.e., $500 \mathrm{~m}$ ), which are in turn directly associated with the maximums in low-level (e.g., $1.5 \mathrm{~km}$ ) vorticity (Fig. 14). This yields the same bulk results as seen in Nielsen and Schumacher (2018, their Fig. 15) where the maximum rotation was seen near $1.5 \mathrm{~km}$ and the maximum acceleration due to the rotation was seen near $500 \mathrm{~m}$. This is additionally shown in the mean vertical cross sections in the analysis simulation (Figs. 18 and 19), where a lowering of the updraft base and a corresponding enhancement of low-level vertical velocities is seen in the regions of lowlevel rotation. While downward acceleration is expected above the level of maximum rotation, it appears, at least in the analysis simulation, that it does not substantially affect the lowering of the updraft base or updraft speeds (Fig. 20) likely due to thermodynamic buoyancy. Overall, these common characteristics between the analysis simulation and Nielsen and Schumacher (2018) imply that the same mechanisms for rain-rate enhancement seen in the idealized simulations of Nielsen and Schumacher (2018) are at work in the horizontally heterogeneous simulation of the Houston Tax Day storm.

The analysis simulation also provided insights into how these dynamical changes associated with rotation might affect the rainfall production mechanisms and microphysical characteristics of the convection. An enhancement is seen in the rainwater mixing ratios in the lower levels of the convection in rotating regions over nonrotating regions and these values increase rapidly as the low-level rotation intensifies (Figs. 18 and 19). On top of this, as the dynamic accelerations associated with rotation are driven by local pressure perturbations (Fig. 20), the dynamic lowering of the pressure in the low-level updraft would also increase the supersaturation of any supersaturated (or near supersaturated) parcels, allowing for increased cloud condensation nuclei activation and condensational growth over a nonrotating storm (e.g., Beard and Ochs 1993). The enhancement of the 
low-level updrafts in the regions of low-level rotation is maintained even with the increase in hydrometeor loading associated with the increase in rainwater mixing ratios in these regions (Figs. 18 and 19). The ability to overcome this increase in resistance to vertical motion was not expected a priori by the authors. However, it again points to the likely importance of the dynamical lift associated with the rotation in maintaining the lowlevel updrafts in this simulation and other such events.

The increase in rainwater mixing ratio and potential increase to supersaturation in the low levels of the storm in rotating regions could also imply that rotation increases the ability to form hydrometeors through warm rain precipitation formation mechanisms, which yield higher precipitation efficiencies compared to ice phased dominated processes (e.g., Tripoli 1982; Levy and Cotton 1984; Lamb 2001; Gochis et al. 2015). This implies that the presence of low-level rotation can increase (or at the very least affect), in certain scenarios, all three terms in Eq. (2) (i.e., $R=E w q$ ) of Doswell et al. (1996) that affect rain rate. The exact influence on the three-term parameter space, of course, depends on many factors. However, situations, such as this case and the ones presented in Nielsen and Schumacher (2018), with significant boundary layer and column moisture, slight stability at low levels, very large values of $0-1 \mathrm{~km}$ shear, moderate CAPE values distributed through the entire troposphere, and deep warm cloud layers might be represent situations where the rotational enhancement effects are greatest, potentially also applying to landfalling tropical cyclone rainbands.

The hydrostatic pressure decrease associated with the reduction of total-column mass due to precipitation might be an important physical process in events that produce such extreme rainfall (Lackmann and Yablonsky 2004). This idea is motivated by the fact that pressure changes, due to sources and sinks of mass from precipitation, evaporation, sublimation, and deposition, are ignored in general because the effects are negligible compared to other processes. However, this assumption may not be correct in heavily precipitating systems, as the hydrostatic pressure equivalent of $25 \mathrm{~mm}$ of rain, which was produced in $5 \mathrm{~min}$ in the Tax Day storm, is approximately $2.5 \mathrm{hPa}$ and was responsible for a large positive potential vorticity (PV) tendency near the melting level for a modeled tropical cyclone (Lackmann and Yablonsky 2004). Thus, it is not unreasonable to expect that a mass sink of this magnitude would be potentially important in extreme rainfall events. Additionally, given that the heaviest precipitating storms in PV space are also associated with convective-scale PV monopoles (i.e., rotating; Chagnon and Gray 2009; Weijenborg et al. 2015, 2017), the connection of this mechanism to PV space provides an additional pathway for positive feedback mechanisms to occur between extreme precipitation and rotation, as discussed in Nielsen and Schumacher (2018). Additional work is warranted to investigate these potential influences further.

In conclusion, this case study shows how meso- $\gamma$-scale rotation associated with intense $0-1 \mathrm{~km}$ shear can lead to the development and maintenance of extreme short-term rainfall rates in a horizontal heterogeneous modeling framework and in an observational analysis of the event. As in the idealized simulations of Nielsen and Schumacher (2018), the rotation was found to seemingly lead to increases in low-level updraft strength, compared to nonrotating regions, and lift parcels that were thermodynamically inhibited that still contained moisture and CAPE. Additionally, the case study presented here showed a corresponding increase, in regions of low-level rotation, of rainwater mixing ratio as the rotation increased, which can lead to an increase in the precipitation efficiency by increasing the presence of warm rain formation. The results of this study offer further evidence of the ability for, even shallow, meso- $\gamma$-scale rotation to dynamically enhance the development and maintenance of extreme rainfall rates in convective scenarios with large values of $0-1 \mathrm{~km}$ shear.

Acknowledgments. The authors thank Gregory Herman, Stacey Hitchcock, and Eric James for their helpful comments/guidance on this work. We would also like to thank Editor Stan Trier and three anonymous reviews for their helpful guidance in improving this manuscript. The Stage-IV data were provided by the National Center for Atmospheric Research (NCAR), which is sponsored by the National Science Foundation. METAR data were provided by the Iowa Environmental Mesonet. HRRR data were provided by the National Oceanic and Atmospheric Administration's Earth System Research Laboratory (ESRL) through the help of Eric James. The RAP analysis was provided by the NOAA's National Centers for Environmental Prediction. The Harris County Flood Warnings System rain gauge data were provided by the Harris County Flood Control District. This research was supported by National Science Foundation Grant AGS-135972; NOAA Grants NA15OAR4590233, NA16OAR4590215, and NA18OAR4590308; and a National Science Foundation Graduate Research Fellowship Grant DGE-1321845, Amendment 3.

\section{REFERENCES}

Ashley, S. T., and W. S. Ashley, 2008: Flood fatalities in the United States. J. Appl. Meteor. Climatol., 47, 805-818, https:// doi.org/10.1175/2007JAMC1611.1.

Atlas, D., 1964: Advances in radar meteorology. Advances in Geophysics, Vol. 10, Academic Press, 317-478, https://doi.org/ 10.1016/S0065-2687(08)60009-6. 
Balakrishnan, N., and D. Zrnić, 1990: Estimation of rain and hail rates in mixed-phase precipitation. J. Atmos. Sci., 47, 565-583, https:// doi.org/10.1175/1520-0469(1990)047<0565:EORAHR >2.0.CO;2.

Beard, K. V., and H. T. Ochs III, 1993: Warm-rain initiation: An overview of microphysical mechanisms. J. Appl. Meteor., 32, 608-625, https://doi.org/10.1175/1520-0450(1993)032<0608: WRIAOO $>2.0 . \mathrm{CO} ; 2$.

Benjamin, S. G., and Coauthors, 2016: A North American hourly assimilation and model forecast cycle: The Rapid Refresh. Mon. Wea. Rev., 144, 1669-1694, https://doi.org/ 10.1175/MWR-D-15-0242.1.

Benoit, M. D., C. J. Nowotarski, D. T. Conlee, and L. Wood, 2018: Impacts of a university-led, on-demand sounding program on human and numerical weather prediction model forecasts in an upper-air observation hole. J. Operational Meteor., 6, 7486, https://doi.org/10.15191/nwajom.2018.0607.

Berry, F., W. Haggard, and P. M. Wolff, 1953: 500-millibar studies at project AROWA. Bull. Amer. Meteor. Soc., 34, 444-453, https://doi.org/10.1175/1520-0477-34.10.444.

Bluestein, H. B., and M. H. Jain, 1985: Formation of mesoscale lines of precipitation: Severe squall lines in Oklahoma during the spring. J. Atmos. Sci., 42, 1711-1732, https://doi.org/ 10.1175/1520-0469(1985)042<1711:FOMLOP > 2.0.CO;2.

Bothwell, P., J. Hart, and R. Thompson, 2002: An integrated threedimensional objective analysis scheme in use at the Storm Prediction Center. Preprints, 21st Conf. on Severe Local Storms, San Antonio, TX, Amer. Meteor. Soc., JP3.1, https://ams.confex.com/ ams/SLS_WAF_NWP/techprogram/paper_47482.htm.

Browning, K., 1977: The structure and mechanism of hailstorms. Hail: A Review of Hail Science and Hail Suppression, Meteor. Monogr., No. 38, Amer. Meteor. Soc., 1-43.

- , and R. Wexler, 1968: The determination of kinematic properties of a wind field using Doppler radar. J. Appl. Meteor., 7, 105-113, https://doi.org/10.1175/1520-0450(1968)007<0105: TDOKPO $>2.0 . \mathrm{CO} ; 2$.

Bunkers, M. J., and C. A. Doswell III, 2016: Comments on "Double impact: When both tornadoes and flash floods threaten the same place at the same time." Wea. Forecasting, 31, 17151721, https://doi.org/10.1175/WAF-D-16-0116.1.

Chagnon, J. M., and S. L. Gray, 2009: Horizontal potential vorticity dipoles on the convective storm scale. Quart. J. Roy. Meteor. Soc., 135, 1392-1408, https://doi.org/10.1002/qj.468.

Chappell, C. F., 1986: Quasi-stationary convective events. Mesoscale Meteorology and Forecasting, P. S. Ray, Ed., Amer. Meteor. Soc., 289-309.

Costa, J. E., 1987: Hydraulics and basin morphometry of the largest flash floods in the conterminous United States. J. Hydrol., 93, 313-338, https://doi.org/10.1016/0022-1694(87)90102-8.

Creutin, J. D., M. Borga, C. Lutoff, A. Scolobig, I. Ruin, and L. Créton-Cazanave, 2009: Catchment dynamics and social response during flash floods: The potential of radar rainfall monitoring for warning procedures. Meteor. Appl., 16, 115125, https://doi.org/10.1002/met.128.

Dalrymple, T., 1937: Major Texas floods of 1935. U.S. Geological Survey Water Supply Paper 796-G, 287 pp.

Davis, R. S., 2001: Flash flood forecast and detection methods Severe Convective Storms, Meteor. Monogr., No. 50, Amer. Meteor. Soc., 481-526, https://doi.org/10.1175/0065-940128.50.481.

Doswell, C. A., III, H. E. Brooks, and R. A. Maddox, 1996: Flash flood forecasting: An ingredients-based methodology. Wea. Forecasting, 11, 560-581, https://doi.org/10.1175/15200434(1996)011<0560:FFFAIB >2.0.CO;2.
Duda, J. D., and W. A. Gallus Jr., 2010: Spring and summer midwestern severe weather reports in supercells compared to other morphologies. Wea. Forecasting, 25, 190-206, https:// doi.org/10.1175/2009WAF2222338.1.

Foote, G., and J. Fankhauser, 1973: Airflow and moisture budget beneath a northeast Colorado hailstorm. J. Appl. Meteor. Climatol., 12, 1330-1353, https://doi.org/10.1175/1520-0450(1973) 012<1330:AAMBBA > 2.0.CO;2.

Fritsch, J. M., and R. Carbone, 2004: Improving quantitative precipitation forecasts in the warm season: A USWRP research and development strategy. Bull. Amer. Meteor. Soc., 85, 955965, https://doi.org/10.1175/BAMS-85-7-955.

Giangrande, S. E., and A. V. Ryzhkov, 2008: Estimation of rainfall based on the results of polarimetric echo classification. J. Appl. Meteor. Climatol., 47, 2445-2462, https://doi.org/ 10.1175/2008JAMC1753.1.

Gochis, D., and Coauthors, 2015: The great Colorado flood of September 2013. Bull. Amer. Meteor. Soc., 96, 1461-1487, https://doi.org/10.1175/BAMS-D-13-00241.1.

Gourley, J. J., and Coauthors, 2017: The FLASH project: Improving the tools for flash flood monitoring and prediction across the United States. Bull. Amer. Meteor. Soc., 98, 361372, https://doi.org/10.1175/BAMS-D-15-00247.1.

Hapuarachchi, H., Q. Wang, and T. Pagano, 2011: A review of advances in flash flood forecasting. Hydrol. Processes, 25, 2771-2784, https://doi.org/10.1002/hyp.8040.

HCFCD, 2019: Harris County Flood Warning System. Accessed 17 January 2019, https://www.harriscountyfws.org/.

Herman, G. R., and R. S. Schumacher, 2018a: Money doesn't grow on trees, but forecasts do: Forecasting extreme precipitation with random forests. Mon. Wea. Rev., 146, 1571-1600, https:// doi.org/10.1175/MWR-D-17-0250.1.

— diction: What random forests and logistic regression tell us about forecasting extreme precipitation. Mon. Wea. Rev., 146, 1785-1812, https://doi.org/10.1175/MWR-D-17-0307.1.

Hitchens, N. M., and H. E. Brooks, 2013: Preliminary investigation of the contribution of supercell thunderstorms to the climatology of heavy and extreme precipitation in the United States. Atmos. Res., 123, 206-210, https://doi.org/10.1016/ j.atmosres.2012.06.023.

Kandel, D., A. Western, R. Grayson, and H. Turral, 2004: Process parameterization and temporal scaling in surface runoff and erosion modelling. Hydrol. Processes, 18, 1423-1446, https:// doi.org/10.1002/hyp.1421.

Kelsch, M., 2001: Hydrometeorological characteristics of flash floods. Coping with Flash Floods, E. Gruntfest and J. Handmer, Eds., Springer, 181-193.

_- E. Caporali, and L. G. Lanza, 2001: Hydrometeorology of flash floods. Coping with Flash Floods, E. Gruntfest and J. Handmer, Eds., Springer, 19-35.

Khain, A., and Coauthors, 2015: Representation of microphysical processes in cloud-resolving models: Spectral (bin) microphysics versus bulk parameterization. Rev. Geophys., 53, 247322, https://doi.org/10.1002/2014RG000468.

Klemp, J. B., W. C. Skamarock, and J. Dudhia, 2007: Conservative split-explicit time integration methods for the compressible nonhydrostatic equations. Mon. Wea. Rev., 135, 2897-2913, https://doi.org/10.1175/MWR3440.1.

Kumjian, M. R., 2013a: Principles and applications of dual-polarization weather radar. Part I: Description of the polarimetric radar variables. J. Operational Meteor., 1, 226-242, https://doi.org/ 10.15191/nwajom.2013.0119. 
2013b: Principles and applications of dual-polarization weather radar. Part II: Warm- and cold-season applications. J. Operational Meteor., 1, 243-264, https://doi.org/10.15191/ nwajom.2013.0120.

Lackmann, G. M., and R. M. Yablonsky, 2004: The importance of the precipitation mass sink in tropical cyclones and other heavily precipitating systems. J. Atmos. Sci., 61, 1674-1692, https://doi.org/10.1175/1520-0469(2004)061<1674: TIOTPM $>2.0 . \mathrm{CO} ; 2$.

Lamb, D., 2001: Rain production in convective storms. Severe Convective Storms, Meteor. Monogr., No. 50, Amer. Meteor. Soc., 299-321, https://doi.org/10.1175/0065-9401-28.50.299.

Levy, G., and W. R. Cotton, 1984: A numerical investigation of mechanisms linking glaciation of the ice-phase to the boundary layer. J. Climate Appl. Meteor., 23, 1505-1519, https://doi.org/ 10.1175/1520-0450(1984)023<1505:ANIOML>2.0.CO;2.

Lin, Y., and K. E. Mitchell, 2005: The NCEP Stage II/IV hourly precipitation analyses: Development and applications. 19th Conf. on Hydrology, San Diego, CA, Amer. Meteor. Soc., 1.2, http://ams.confex.com/ams/pdfpapers/83847.pdf.

Lindner, J., and S. Fitzgerald, 2016: Harris Country Flood Control District: Tax day flood immediate report. Tech. Memo., 34 pp.

Lorenz, E. N., 1969: The predictability of a flow which possesses many scales of motion. Tellus, 21A, 289-307, https://doi.org/ 10.1111/j.2153-3490.1969.tb00444.x.

Maddox, R. A., C. F. Chappell, and L. R. Hoxit, 1979: Synoptic and meso- $\alpha$ scale aspects of flash flood events. Bull. Amer. Meteor. Soc., 60, 115-123, https://doi.org/10.1175/1520-0477-60.2.115.

Markowski, P., and Y. Richardson, 2010: Mesoscale Meteorology in Midlatitudes. Wiley-Blackwell, $430 \mathrm{pp}$.

Marwitz, J. D., 1972: Precipitation efficiency of thunderstorms on the high plains. J. Rech. Atmos., 6, 367-370.

Melhauser, C., and F. Zhang, 2012: Practical and intrinsic predictability of severe and convective weather at the mesoscales. J. Atmos. Sci., 69, 3350-3371, https://doi.org/10.1175/JAS-D-11-0315.1.

Mellor, G. L., and T. Yamada, 1982: Development of a turbulence closure model for geophysical fluid problems. Rev. Geophys., 20, 851-875, https://doi.org/10.1029/RG020i004p00851.

Meng, Z., and D. Yao, 2014: Damage survey, radar, and environment analyses on the first-ever documented tornado in Beijing during the heavy rainfall event of 21 July 2012. Wea. Forecasting, 29, 702-724, https://doi.org/10.1175/WAF-D-1300052.1.

Milrad, S. M., E. H. Atallah, J. R. Gyakum, and J. Klepatzki, 2019: The extreme precipitation index (EPI): A coupled dynamic-thermodynamic metric to diagnose midlatitude floods associated with flow reversal. Wea. Forecasting, 34, 1257-1276, https://doi.org/10.1175/WAF-D-18-0156.1.

Mlawer, E. J., S. J. Taubman, P. D. Brown, M. J. Iacono, and S. A. Clough, 1997: Radiative transfer for inhomogeneous atmospheres: RRTM, a validated correlated-k model for the longwave. J. Geophys. Res., 102, 16 663-16 682, https://doi.org/ 10.1029/97JD00237.

Mohamadi, M. A., and A. Kavian, 2015: Effects of rainfall patterns on runoff and soil erosion in field plots. Int. Soil Water Conserv. Res., 3, 273-281, https://doi.org/10.1016/j.iswcr.2015.10.001.

Nakanish, M., 2001: Improvement of the Mellor-Yamada turbulence closure model based on large-eddy simulation data. Bound.-Layer Meteor., 99, 349-378, https://doi.org/10.1023/A: 1018915827400

Nakanishi, M., and H. Niino, 2004: An improved Mellor-Yamada level-3 model with condensation physics: Its design and verification.
Bound.-Layer Meteor., 112, 1-31, https://doi.org/10.1023/B: BOUN.0000020164.04146.98.

Namias, J., 1951: The great Pacific anticyclone of winter 1949-50: A case study in the evolution of climatic anomalies. J. Meteor., 8, 251-261, https://doi.org/10.1175/1520-0469(1951)008<0251: TGPAOW $>2.0 . \mathrm{CO} ; 2$.

Nielsen, E. R., 2016: Using convection-allowing ensembles to understand the predictability of extreme rainfall. M.S. thesis, Department of Atmospheric Sciences, Colorado State University, Fort Collins, CO, $168 \mathrm{pp}$.

- 2019: Insights into extreme short-term precipitation associated with supercells and mesovortices. Ph.D. thesis, Colorado State University, Fort Collins, CO, $182 \mathrm{pp}$.

— sembles to understand the predictability of an extreme rainfall event. Mon. Wea. Rev., 144, 3651-3676, https://doi.org/ 10.1175/MWR-D-16-0083.1.

, and _ 2018: Dynamical insights into extreme short-term precipitation associated with supercells and mesovortices. J. Atmos. Sci., 75, 2983-3009, https://doi.org/10.1175/JAS-D17-0385.1.

—, and —- 2019: Observations of extreme short-term precipitation associated with supercells and mesovortices. Mon. Wea. Rev., 148, 159-182, https://doi.org/10.1175/MWR-D-19-0146.1.

_ G. R. Herman, R. C. Tournay, J. M. Peters, and R. S. Schumacher, 2015: Double impact: When both tornadoes and flash floods threaten the same place at the same time. Wea. Forecasting, 30, 1673-1693, https://doi.org/10.1175/WAF-D-15-0084.1.

,,,$--- \ldots$, and _ 2016a: Reply to "Comments on 'Double impact: When both tornadoes and flash floods threaten the same place at the same time."' Wea. Forecasting, 31, 1723-1727, https://doi.org/10.1175/WAF-D-16-0151.1.

- R. S. Schumacher, and A. M. Keclik, 2016b: The effect of the Balcones Escarpment on three cases of extreme precipitation in central Texas. Mon. Wea. Rev., 144,119-138, https://doi.org/ 10.1175/MWR-D-15-0156.1.

NOAA, 2016: Storm Data. Vol. 58, No. 4, 377 pp.

Novak, D. R., C. Bailey, K. Brill, M. Eckert, D. Petersen, R. Rausch, and M. Schichtel, 2011: Human improvement to numerical weather prediction at the Hydrometeorological Prediction Center. 24th Conf. on Weather and Forecasting/20th Conference on Numerical Weather Prediction, 440, Seattle, WA, Amer. Meteor. Soc., https://ams.confex.com/ams/ 91Annual/webprogram/Paper181989.html.

NWS, 2018a: Service assessment: August/September 2017 Hurricane Harvey. National Weather Service, 78 pp. https://www.weather.gov/media/publications/assessments/ harvey6-18.pdf.

__ 2018b: Summary of natural hazard statistics in the United States. Climate, Weather, and Water Services, National Weather Service, accessed 13 November 2018, https://www.weather.gov/ hazstat/.

Perica, S., S. Pavlovic, M. St. Laurent, C. Trypaluk, D. Unruh, and O. Wilhite, 2018: Precipitation-Frequency Atlas of the United States. NOAA Atlas 14, Vol. 11, Version 2.0, NOAA, 283 pp.

Saharia, M., P.-E. Kirstetter, H. Vergara, J. J. Gourley, Y. Hong, and M. Giroud, 2017: Mapping flash flood severity in the United States. J. Hydrometeor., 18, 397-411, https://doi.org/ 10.1175/JHM-D-16-0082.1.

Schroeder, A., J. Basara, J. M. Shepherd, and S. Nelson, 2016: Insights into atmospheric contributors to urban flash flooding across the United States using an analysis of rawinsonde 
data and associated calculated parameters. J. Appl. Meteor. Climatol., 55, 313-323, https://doi.org/10.1175/JAMC-D-140232.1.

Schumacher, R. S., 2009: Mechanisms for quasi-stationary behavior in simulated heavy-rain-producing convective systems. J. Atmos. Sci., 66, 1543-1568, https://doi.org/10.1175/2008JAS2856.1.

_- 2017: Heavy rainfall and flash flooding. Natural Hazard Science: Oxford Research Encyclopedias, 40 pp., https://doi.org/ 10.1093/acrefore/9780199389407.013.132.

— properties of extreme-rain-producing mesoscale convective systems. Mon. Wea. Rev., 133, 961-976, https://doi.org/ 10.1175/MWR2899.1.

— convective systems associated with midlevel cyclonic circulations. Wea. Forecasting, 24, 555-574, https://doi.org/10.1175/ 2008WAF2222173.1.

Skamarock, W., and J. B. Klemp, 2008: A time-split nonhydrostatic atmospheric model for weather research and forecasting applications. J. Comput. Phys., 227, 3465-3485, https://doi.org/ 10.1016/j.jcp.2007.01.037.

— search WRF version 3. NCAR Tech. Note NCAR/TN475+STR, 113 pp., https://doi.org/10.5065/D68S4MVH.

Smirnova, T. G., J. M. Brown, and S. G. Benjamin, 1997: Performance of different soil model configurations in simulating ground surface temperature and surface fluxes. Mon. Wea. Rev., 125, 1870-1884, https://doi.org/10.1175/1520-0493(1997) 125<1870:PODSMC $>2.0$. CO 2 .

,,--- , and D. Kim, 2000: Parameterization of coldseason processes in the maps land-surface scheme. J. Geophys. Res., 105, 4077-4086, https://doi.org/10.1029/1999JD901047.

,,,--- and J. S. Kenyon, 2016: Modifications to the rapid update cycle land surface model (RUC LSM) available in the weather research and forecasting (WRF) model. Mon. Wea. Rev., 144, 1851-1865, https://doi.org/10.1175/MWR-D-15-0198.1.

Smith, J. A., M. L. Baeck, Y. Zhang, and C. A. Doswell III, 2001: Extreme rainfall and flooding from supercell thunderstorms. J. Hydrometeor., 2, 469-489, https://doi.org/10.1175/15257541(2001)002<0469:ERAFFS $>2.0$.CO;2.

— , A. A. Cox, M. L. Baeck, L. Yang, and P. Bates, 2018: Strange floods: The upper tail of flood peaks in the United States. Water Resour. Res., 54, 6510-6542, https://doi.org/10.1029/ 2018WR022539.

- M. L. Baeck, L. Yang, J. Signell, E. Morin, and D. C. Goodrich, 2019: The paroxysmal precipitation of the desert: Flash floods in the Southwestern United States. Water Resour. Res., https://doi.org/10.1029/2019WR025480, in press.
Smith, T. L., S. G. Benjamin, J. M. Brown, S. Weygandt, T. Smirnova, and B. Schwartz, 2008: Convection forecasts from the hourly updated, 3-km high resolution rapid refresh model. Preprints, 24th Conf. on Severe Local Storms, Savannah, GA, Amer. Meteor. Soc., 11.1, http://ams.confex.com/ams/ 24SLS/techprogram/paper_142055.htm.

SPC, 2018: Storm Prediction Center: Archive national sector hourly mesoscale analysis. NOAA, accessed 28 September 2018, www.spc.noaa.gov/exper/ma_archive/images_s4.

Špitalar, M., J. J. Gourley, C. Lutoff, P.-E. Kirstetter, M. Brilly, and N. Carr, 2014: Analysis of flash flood parameters and human impacts in the US from 2006 to 2012. J. Hydrol., 519, 863-870, https://doi.org/10.1016/j.jhydrol.2014.07.004.

Sui, C.-H., X. Li, and M.-J. Yang, 2007: On the definition of precipitation efficiency. J. Atmos. Sci., 64, 4506-4513, https:// doi.org/10.1175/2007JAS2332.1.

Terti, G., I. Ruin, S. Anquetin, and J. J. Gourley, 2017: A situationbased analysis of flash flood fatalities in the United States. Bull. Amer. Meteor. Soc., 98, 333-345, https://doi.org/10.1175/ BAMS-D-15-00276.1.

Thompson, G., and T. Eidhammer, 2014: A study of aerosol impacts on clouds and precipitation development in a large winter cyclone. J. Atmos. Sci., 71, 3636-3658, https://doi.org/ 10.1175/JAS-D-13-0305.1.

Tripoli, G., 1982: The Colorado State University three-dimensional cloud/mesoscale model-1982. Part I: General theoretical framework and sensitivity experiments. J. Rech. Atmos., 16, 185-219.

Ware, R. H., and Coauthors, 2000: SuomiNet: A real-time national GPS network for atmospheric research and education. Bull. Amer. Meteor. Soc., 81, 677-694, https://doi.org/10.1175/15200477(2000)081<0677:SARNGN > 2.3.CO;2.

Weijenborg, C., P. Friederichs, and A. Hense, 2015: Organisation of potential vorticity on the mesoscale during deep moist convection. Tellus, 67A, 25705, https://doi.org/10.3402/ tellusa.v67.25705.

—, J. Chagnon, P. Friederichs, S. Gray, and A. Hense, 2017: Coherent evolution of potential vorticity anomalies associated with deep moist convection. Quart. J. Roy. Meteor. Soc., 143, 1254-1267, https://doi.org/10.1002/qj.3000.

Zhang, F., A. M. Odins, and J. W. Nielsen-Gammon, 2006: Mesoscale predictability of an extreme warm-season precipitation event. Wea. Forecasting, 21, 149-166, https://doi.org/ 10.1175/WAF909.1.

Zhang, J., and Coauthors, 2016: Multi-Radar Multi-Sensor (MRMS) quantitative precipitation estimation: Initial operating capabilities. Bull. Amer. Meteor. Soc., 97, 621-638, https://doi.org/10.1175/BAMS-D-14-00174.1. 